WIDER Working Paper 2019/63

\title{
Dancing with dragons
}

Chinese import penetration and the performances of manufacturing firms in South Africa

Sofia Torreggiani ${ }^{1}$ and Antonio Andreoni ${ }^{1,2}$

September 2019 
Abstract: Using firm-level tax administrative data from 2010 to 2017, we study the impact of Chinese import penetration on the performances of manufacturing firms in South Africa, and whether firms investing in capabilities development are more resilient to such competitive pressure. Specifically, by instrumenting Chinese import penetration with China's share in other low- and middle-income countries' imports, we first explore whether Chinese import exposureboth direct (e.g. affecting the sector in which the firm itself operates) and indirect (e.g. through input-output linkages along the domestic value chain)-have been associated with firms downsizing in terms of decreasing employment and sales growth and higher probability of exiting the market. Second, we examine whether firms investing in process and product innovation and skills development perform better in response to import competition. Our results indicate that rising Chinese import exposure — not only direct, but also in downstream segments of the domestic value chain-leads to slower sales and employment growth for the entire sample of surviving firms and to higher probability of shutdown for firms not undertaking any spending in capabilities development. However, we also find that the negative impact of Chinese import penetration is partially mitigated by investments in capital, innovation, and skills development.

Key words: capabilities, Chinese import competition, direct and indirect import penetration, manufacturing, South Africa

JEL classification: D22, F14, F61, F63, L25

Acknowledgements: We would like to thank all the participants at the SA-TIED-South African National Treasury-UNU-WIDER-South African Revenue Service Policy Seminar', 22 January 2019, and at the SA-TIED Work-in-Progress Meeting, 29 January 2019, for their comments, inputs, and suggestions. Support from UNU-WIDER is gratefully acknowledged.

${ }^{1}$ SOAS University of London, London, UK; ${ }^{2}$ University of Johannesburg, South Africa. Corresponding author: s_torreggiani@soas.ac.uk.

This study has been prepared within the UNU-WIDER project Southern Africa — Towards inclusive economic development (SA-TIED).

Copyright (C) UNU-WIDER 2019

Information and requests: publications@wider.unu.edu

ISSN 1798-7237 ISBN 978-92-9256-697-5

https://doi.org/10.35188/UNU-WIDER/2019/697-5

Typescript prepared by Gary Smith.

The United Nations University World Institute for Development Economics Research provides economic analysis and policy advice with the aim of promoting sustainable and equitable development. The Institute began operations in 1985 in Helsinki, Finland, as the first research and training centre of the United Nations University. Today it is a unique blend of think tank, research institute, and UN agency providing a range of services from policy advice to governments as well as freely available original research.

The Institute is funded through income from an endowment fund with additional contributions to its work programme from Finland, Sweden, and the United Kingdom as well as earmarked contributions for specific projects from a variety of donors.

Katajanokanlaituri 6 B, 00160 Helsinki, Finland

The views expressed in this paper are those of the author(s), and do not necessarily reflect the views of the Institute or the United Nations University, nor the programme/project donors. 
The opportunities and challenges associated with increasing South-South trade and global value chain (GVCs) integration have gained centre-stage in the academic and policy debate across developing countries. China looms large in these discussions, given the massive gains in its world manufacturing share since the mid-1990s (Haraguchi et al. 2017), and the increasing domestic value-added content of its exports since the mid-2000s. In 2016, China accounted for almost 50 per cent of total South-South exports (UNCTAD 2017), while its domestic value-added in gross exports of manufacturing to non-OECD (Organisation for Economic Co-operation and Development) economies increased from around 70 per cent in 2005 to over 81 per cent in 2015 (OECD-TiVA 2018).

The dramatic expansion in Chinese commercial weight (Lin 2011), and the country's ongoing upgrading from global assembler to parts provider and system integrator along GVCs, even in some advanced manufacturing technology segments (Fu 2016; Tassey 2014; Zhou et al. 2016), opens up important questions on its impact on the rest of the world. This is particularly the case for less developed countries witnessing 'primarization dynamics' and middle-income economies experiencing premature deindustrialization and deteriorating trade imbalances. An often-raised concern is that increasing competitive pressure exerted by Chinese imports on manufacturing industries in other developing countries with weak technology and production capability bases might limit the breadth and depth of their industrial development (Andreoni 2019; Kaplinsky 2008; Lall and Alaladejo 2004; Lall and Weiss 2005).

Over the past decade, there has been an increasing amount of empirical literature investigating the effects of Chinese import competition on firm performances in advanced economies (Bernard et al. 2006; Bloom et al. 2016; Hombert and Matray 2018; Mion and Zhu 2013). However, due to limited longitudinal micro-datasets, only a few studies have been able to produce econometric evidence on the impact of Chinese import competition for low- and middle-income countries (Alvarez and Claro 2009; Iacovone et al. 2013).

The recent availability of tax administrative data for South Africa-based companies allows us to contribute to filling this knowledge gap and to generate new evidence on the impact of Chinese import penetration on manufacturing firms in a major middle-income country. To the best of our knowledge this is the first empirical firm-level study investigating this issue in South Africa. This country provides an excellent policy-relevant case study. Since the end of the apartheid period in South Africa, the increasing integration into the global economy and the ongoing intensification of import competition from China have gone hand-in-hand with severe unemployment, poor growth performance, and persistent structural transformation challenges (Andreoni and Tregenna 2018).

Following China's accession to the World Trade Organization (WTO) in 2001, trade relations between South Africa and China have deepened rapidly. In 2009, China became South Africa's first export destination, overtaking the United States, and its largest supplier of imports, outperforming Germany. These imports consist overwhelmingly of manufacturing products, while South Africa's exports to China are primarily natural resources and raw materials. Furthermore, while during the mid-1990s China represented a major source of imports in the traditional low-technology and labour-intensive sectors-such as textiles, clothing, and footwear-by the 2010s Chinese import penetration increasingly shifted towards medium- and high-technology products such as electronics and machinery. The surge in trade structure imbalances and the evolving composition of these bilateral trade flows have prompted an active debate about the deindustrialization and 'primarization' trajectories of the South African economy, its impact 
on domestic manufacturing production and employment, as well as the future terms of engagement with China. ${ }^{1}$

Figure 1 reports, on the one hand, the surge of Chinese manufacturing imports entering South Africa and, on the other hand, suggestive evidence of the shrinkage of the domestic manufacturing sector. China's import penetration levels have increased significantly from a negligible 1.45 per cent in 2002 to more than 8 per cent in $2017,{ }^{2}$ while the shares of manufacturing in total output and employment have constantly declined. Between 2002 and 2017, both the fraction of manufacturing output and of South African workers employed in manufacturing fell by over one-quarter, from 33.4 per cent to 23.9 per cent, and from 16.8 per cent to 12.2 per cent, respectively.

Figure 1: Trends in manufacturing output, employment, and Chinese import exposure in South Africa, 2002-17.

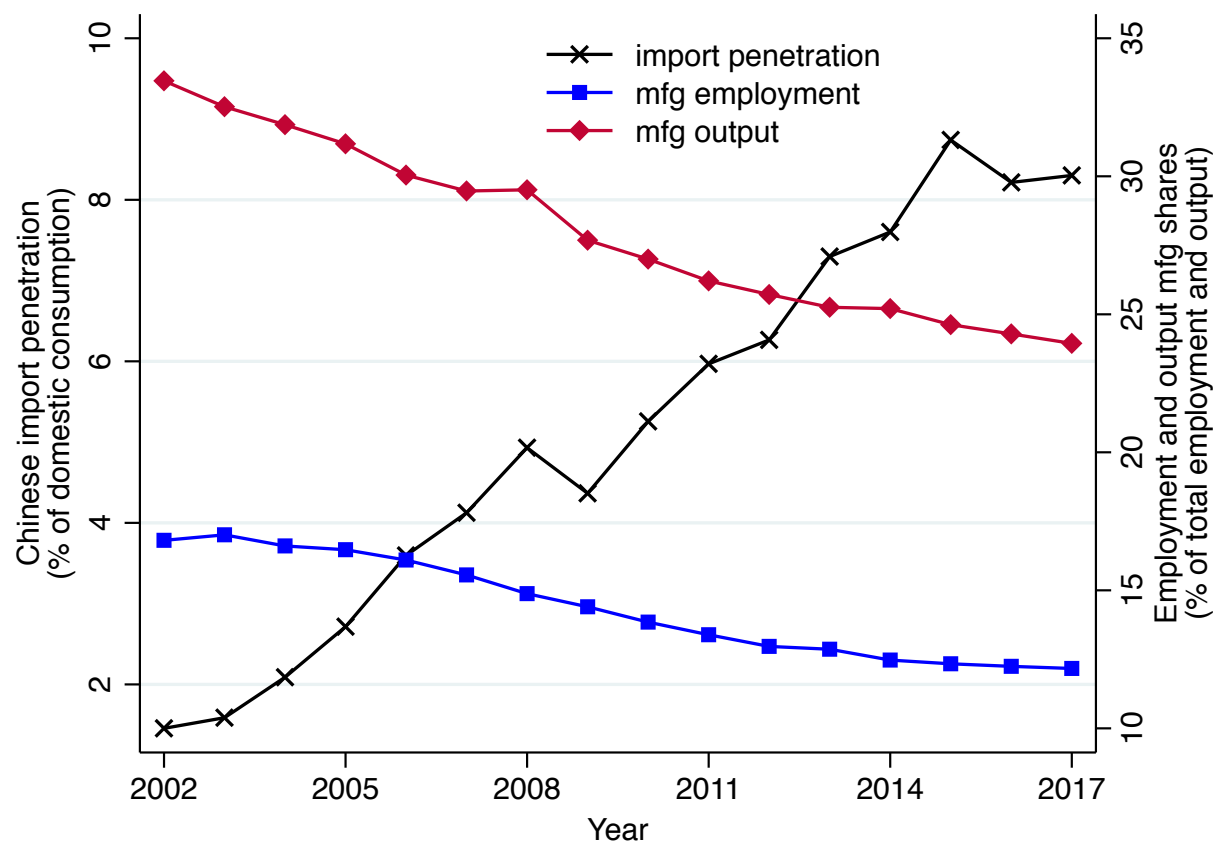

Notes: the import penetration ratio for South African imports from China (left scale), share of South African manufacturing output (employment) in total output (employment) (right scale).

Source: authors' calculations using UN Comtrade (2018), Statistics South Africa (2018a,b).

Despite these concerns, there have been no comprehensive studies that attempt to investigate the impact of Chinese import penetration on the performance of manufacturing firms in South Africa. In this paper, using a unique firm-level database recently made available by the South African Revenue Service (SARS), we study: (1) whether China's import penetration-both direct (e.g. affecting the sector where the firm itself operates) and indirect (e.g. through input-output linkages from upstream and downstream sectors) - have been associated with a downsizing of manufacturing firms in terms of decreasing employment and sales growth, and higher probability of exiting the market; and (2) whether firms invest-

\footnotetext{
${ }^{1}$ For example, during the Forum on China-Africa Cooperation (FOCAC) in 2012, held in Beijing, the former President Zuma commented that an unequal trade relationship based on the supply of raw materials by South Africa was unsustainable (Mail $\&$ Guardian 2012). On the occasion of the third edition of the same event, in September 2018, President Ramaphosa reemphasized the importance of balancing the structure of trade with China (South African Government 2018). Furthermore, the negotiations for a free trade agreement between China and South Africa, first initiated in 2004, have been subsequently abandoned primarily due to concerns among South African and other regional stakeholders (e.g. business associations and unions, among others). However, recently, official discussions on a free trade agreement between China and countries of the Southern Africa Customs Union (SACU) resurfaced on the trade agenda.

${ }^{2}$ In Figure 1, we define import penetration as South African manufacturing imports from China divided by total South African domestic expenditure on manufacturing goods, measured as gross output plus total imports minus total exports. See the subsection 'Measuring direct import exposure' for further details.
} 
ing in technology and productive capabilities-notably process and product innovation, but also skills development-are more resilient to Chinese import competition. Due to micro-data limitations, our analysis is restricted to the post-2009 years, in the aftermath of the global financial crisis. In developing our methodology, we build and expand upon previous works by Acemoglu et al. (2016), Alvarez and Claro (2009), Autor et al. (2013), Bernard et al. (2006), Hombert and Matray (2018), and Iacovone et al. (2013).

The rest of the paper is organized as follows. Section 2 reviews the relevant literature on the impact of import competition on countries' domestic production system, in particular those studies focusing on the effects on manufacturing firm performance. We contextualize this literature by considering the specific ways in which a surge in Chinese import penetration can impact relatively less developed industrial systems like South Africa. In Section 3 we develop a simple analytical framework guiding the formulation of testable hypotheses and the following empirical strategy. The latter is discussed in Section 4, where the data are also introduced. Section 5 presents some preliminary descriptive analysis, highlighting (1) the main characteristics of the Chinese competitive pressure on the South African manufacturing sector in the aftermath of the global financial crisis, and (2) some statistics on firm investment in capital equipment, innovation activity, and skills development programs. The main econometric findings are summarized and analysed in Section 6. Finally, Section 7 concludes, discussing some policy implications.

Literature review

A large body of literature has analysed the impact of import competition on the domestic production systems of both developed and developing countries. Since China's surge in international trade, several studies have focused on the impact of Chinese import penetration on different dimensions and levels of aggregation in the production system-for example, plants, firms, and industries, but also local labour markets. Several studies on industries and local labour markets document the contractionary effects on manufacturing employment of the competitive pressure driven by the surge of Chinese imports, in both developed (Acemoglu et al. 2016; Autor et al. 2013; Balsvik et al. 2015; Donoso et al. 2015; Malgouyers 2016) and developing countries (Mendez 2015; Paz 2018). Other plant-level and firm-level studies find similar negative effects of increasing Chinese import penetration in terms of employment growth, output growth, and survival rates in the manufacturing sector. In an influential treatment of trade impacts on US manufacturing, Bernard et al. (2006) find that, over the period 1977-97, plants more exposed to import competition from low-wage countries - with China being the largest member of this group by far-grew more slowly and were more likely to exit the market. Similarly, results by Mion and Zhu (2013) on Belgian manufacturing firms between 1996 and 2007 indicate that industry-level import competition from China reduces firm employment growth, while not affecting firm survival. Due to the limited availability of extensive firm-level longitudinal datasets across developing economies, however, we have limited knowledge of the impact of Chinese import penetration on manufacturing firms located in these countries. One of the few systematic studies was conducted by Alvarez and Claro (2009), who find that, over the period 1990-2000, Chinese import penetration has driven a decline in employment growth and survival rates for firms in the Chilean manufacturing sector. ${ }^{3}$ An additional empirical assessment is

\footnotetext{
${ }^{3}$ Contrary to both the predictions of the factor-endowment-driven specialization framework and the empirical evidence for advanced economies (Bernard et al. 2006; Mion and Zhu 2013), Alvarez and Claro (2009) do not find evidence of any procompetitive and upgrading effect on capital and skill deepening, productivity catch-up, or increased exporting activities. They associate these negative findings with the low levels of capital and skilled labour, which may have limited the ability of Chilean firms to move towards more sophisticated products in response to import competition.
} 
conducted by Iacovone et al. (2013), who evaluate the effects of increasing Chinese import competition for producers in another middle-income country such as Mexico, taking into account firm heterogeneity in terms of size. Employing a quantile regression approach, they show that sales of smaller plants and more marginal products shrink substantially and are more likely to further decline toward zero, whereas those of larger plants and core products seem relatively more resilient to the increased import competition.

There is little evidence, however, on the specific features that allow certain firms to better cope with rising import penetration. Notable exceptions-but only for developed countries-are represented by the works of Bernard et al. (2006) and Mion and Zhu (2013), who show that capital- and skill-intensive plants in the United States and Belgium, respectively, are more likely to survive and grow in light of increasing import competition, consistent with the predictions of the firm-level variant of the HeckscherOhlin model reported by Bernard et al. (2006). ${ }^{4}$ We complement this literature by explicitly testing the relevance of the mediating role of production and technology capabilities on the relationship between import competition and firm performance. Indeed, while capital and skill endowments are of paramount importance, our conjuncture points to a more complex set of features of the South African industrial system and specific competitive challenges affecting its extremely heterogeneous firms. Capability theories of the firm (Andreoni 2014; Dosi et al. 1990, 2000; Lall 1992, 1999; Lin and Chang 2009; Penrose 1959) suggest how firms' reactions to competitive pressure critically depends on their internal capabilities, specifically how they organize these capabilities in response to changing opportunities, incentives, and rising challenges. These authors have emphasized the importance of production and technology capabilities (e.g. skills, physical investments, technological efforts) for firms to manage and advance technological change (Bell and Pavitt 1993; Lall 1992; Penrose 1959), to absorb external sources of knowledge (Cohen and Levinthal 1989), and to benefit from participation in trade (Dosi et al. 1990; Lall 1999) and GVCs (Andreoni 2019; Lee et al. 2018; Milberg and Deborah 2013; Morrison et al. 2008). In a recent study, Hombert and Matray (2018) start shedding some light on the role of specific firmlevel characteristics in mitigating the impact of Chinese import competition on US manufacturing plants from 1991 to 2007. They show that firms with larger stocks of R\&D (research and development) are more resilient to such trade shocks, downsizing considerably less. We add to this emerging literature by estimating the impact of Chinese import competition on South Africa-based manufacturing firms conditional on a battery of firm-level capabilities-related proxies such as capital investment, expenditures in internal (e.g. R\&D) and external (e.g. royalties) innovation activities and in skills development (e.g. training).

Our work also relates to the literature focusing on the diffusion of shocks (Acemoglu et al. 2012; Contreras and Fagiolo 2014) and foreign direct investment (FDI) spillovers (Javorcik 2004; Javorcik and Spatareanu 2011; Newman et al. 2015) through the input-output network of an economy. Following a methodology similar to the one developed by Acemoglu et al. (2016) and Pierce and Schott (2016), in our empirical analysis we also take into account the indirect effects of such competitive pressure arising from input-output linkages in downstream and upstream industries affected by increasing Chinese import penetration. ${ }^{5}$ The importance of disentangling this form of indirect impact is also inspired by multisectoral models and industrial development contributions emphasizing the importance of these intersectoral linkages in countries' economic structures and how a number of different shocks (e.g. targeted policies, investments, opening to trade, linking to GVCs), acting upon these industrial interdependen-

\footnotetext{
${ }^{4}$ However, within the context of middle-income countries, Alvarez and Claro (2009) do not find evidence of any reallocation effect towards relatively more capital- and skill-intensive firms.

${ }^{5}$ However, the specifications proposed by Acemoglu et al. (2016) and Pierce and Schott (2016) differ in some essential respects from ours. Acemoglu et al. (2016), in particular, regress the change in log employment at the level of the manufacturing industries (rather than firms) on changes in the Chinese import penetration rate (rather than its previous level).
} 
cies, might force countries towards extremely diverse development paths (Andreoni 2019; Hirschman 1958, 1997).

In the post-apartheid period, rapid trade liberalization represented a major shock for South African industries. Since then, the lack of dynamism of the manufacturing sector has been regarded as a key factor in explaining stagnant growth and persistently high unemployment levels (Andreoni and Tregenna 2018; Fedderke 2006; Rodrik 2008; Tregenna 2016). These weak performances and various other signs of premature deindustrialization have been also associated with the competitive pressure from imports resulting from the multilateral trade reform of the early 1990s (Erten et al. 2019; Rodrik 2008) and, more recently, from the rapid growth in imports from China following its accession to the WTO in 2001 (Edwards and Jenkins 2015; Jenkins 2008). Detailed sectoral analysis and case studies of the implications of Chinese imports for South Africa generally find adverse effects on domestic production and employment and a crowding out of exports to third countries (Edwards and Jenkins 2014, 2015; Jenkins 2008; Morris and Einhorn 2008). In particular, on the one hand, Morris and Einhorn (2008) show how import competition from China in the South African clothing and textile sector facilitates production upgrading and enhances consumer welfare, while leading to the erosion of productive capabilities in the domestic industry. On the other hand, using Chenery-style decomposition techniques, Edwards and Jenkins (2015) document that labour-intensive industries exposed to import competition from China suffered large employment declines from 1992 to 2010. Overall, studies within the literature suggest that the competitive pressure exerted by Chinese exports to South Africa has increased rapidly over the past decades, partly at the expense of imports from third countries, but more importantly crowding out domestic manufacturing production. While these works provide important industry-specific evidence of the effect of import penetration from China, detailed case studies cannot be easily generalized and sectoral-level analyses employing decomposition techniques do not shed any light on firm-level heterogeneous dynamics triggered by Chinese import penetration. In particular, they do not allow testing of a number of hypotheses related to the performance of manufacturing firms and how their different capabilities play a mediating role. Our study, on the contrary, fills this gap in the literature by providing the first micro-level evidence of the direct and indirect impacts of Chinese competitive pressure on the performance of South Africa-based manufacturing firms.

\section{Conceptual framework}

International competition, in particular exposure to international trade, is a key potential determinant of manufacturing firm dynamics, of both their growth and upgrading as much as their decline and disappearance. Under specific assumptions, in neoclassical trade theory and different variants of the standard $\mathrm{H}-\mathrm{O}-\mathrm{S}$ (Heckscher-Ohlin-Samuelson) model, international trade competition is seen as the main vehicle through which countries specialize along their comparative advantage and effectively engage in 'trade in products' across countries (Krugman 1980) and, more recently, 'trade in tasks' along GVCs (Baldwin and Robert-Nicoud 2014).

Since the 1950s, developmentalist theories have pointed to the limitations and shortcomings of these models, especially when it comes to developing and emerging economies, and reflected on the historical structural change trajectories of countries like Japan, South Korea, and China (Lin and Chang 2009). While these contributions acknowledge the learning and external demand opportunities offered by access to international trade and exposure to international competition, they also point to a set of more nuanced factors, mediating processes, and dynamics. First, they emphasize how to capture international trade opportunities-in particular, firms in developing and emerging countries must strategically engage in international trade. This means committing resources to catching-up capability development focusing 
on short learning cycles (Lee 2013). Second, they highlight how industrial and trade policies play a role in this engagement by supporting firm-level capability development (Andreoni and Chang 2019). Third, they point to the fact that exposure to international trade competition will have disproportionate effects across sectors and firms, reflecting the high level and multiple dimensions of heterogeneity characterizing different manufacturing industries and types of firms (Dosi et al. 1990). Fourth, they suggest how the impact of international trade competition is prone to affecting internal firm dynamics as much as the overall production system made of inter-firm linkages, in particular those mediated by input-output relationships. Finally, they point to the concentration tendencies in manufacturing industries driven by technologies, scale economies, and path-dependency, and thus the changing nature of international trade competition in different market, product, and technology-intensity segments.

These more nuanced theoretical and empirical insights have gained some traction since the mid-2000s, with the increasing import penetration from China in both developed and developing countries (Cherif and Hasanov 2019). In building up our conceptual framework for assessing the firm-level impact of Chinese import penetration across developing and emerging economies and formulating a number of testable hypotheses, we build on some of these more nuanced insights. The reason is that they better reflect the competitive position of firms in countries like South Africa and a number of features of its production system. Thus, they suggest ways in which firms might be directly and indirectly affected by Chinese import penetration, and the potential mediating factors to consider.

Developing and middle-income economies tend to present a quite skewed industrial structure, with a few major players operating as OEMs (original equipment manufacturers) and a limited number of mediumsized firms directly supplying them (so-called 'missing middle'). The export orientation of smaller firms is limited and they tend to depend mainly on domestic and, in a limited number of cases and for a few product segments, some regional markets. Related to their market presence, firms' investments in productive and technological capabilities development are also limited and discontinuous. As a result of the weak competitive position of firms in these countries, we expect that the increasing pressure from China will result in a reduction of their employment growth rates, as well as of their sales growth. These are two key metrics of firms' expansionary dynamics. The first two hypotheses we formulate point to the possibility of a negative direct impact of Chinese import penetration on firms, showing the characteristics described above in terms of market dependence and limited capability investments. The extreme case hypothesis is one of import competitive pressure increasing the chances for firms of this type to exit the market. This is our third hypothesis. ${ }^{6}$

The fourth hypothesis is, however, that companies committing resources in various capability development activities might be better equipped in responding to import competition pressure. In our conceptual framework the mediated role of capability development activities can operate in different ways. For example, firms might invest in process efficiency improvements, or in product customization or changes in product functionalities. In other cases, firms might make investments to shift towards activities that are not directly affected by import penetration. For example, they may reposition themselves along the value chain, either downstream towards the provision of post-sale services or upstream through development of customized solutions requiring co-location in the domestic market. The testable empirical strategy is, however, simply one capturing the extent to which different investments mediate the impact of import penetration, independently of how these investments specifically reshape firms' competitive strategies.

Firms are not only heterogeneous in their competitive positions and strategic investment decisions. They are also linked by several types of linkages - upstream with their suppliers, and downstream with their clients. The final testable hypothesis is thus that, given the existence of these linkages, import pene-

\footnotetext{
6 This 'direct effect' refers to the reduction in employment and sales growth and survival rates for firms whose outputs directly compete with Chinese imports (e.g. firms operating in the sector within which products imported from China are classified).
} 
tration might affect firms' expansionary dynamics indirectly. Specifically, we can expect that import penetration affecting a firm's downstream clients (e.g. upstream effects) might reduce the demand of these clients for the intermediate or final products produced by the same firms. Furthermore, the increase of competition from imports affecting a firm's upstream suppliers (e.g. downstream effects), on the one hand, might exert a downward pressure on input prices, having an expansionary effect on the activities of the procuring firm itself (Goldberg et al. 2010), while, on the other hand, it might lead to the disruption of existing long-term supply agreements for specialized inputs, having a contractionary effect.

In sum, our conceptual framework, graphically represented in Figure 2, points to the existence of both direct and indirect channels through which import penetration might affect a firm's expansionary dynamics in employment and sales, and the likelihood of its exit from the market. It also points to the fact that mediating factors related to capabilities development activities might lead to disproportional dynamics and heterogeneous effects across firms.

Figure 2: The impact of direct and indirect Chinese import penetration on manufacturing firms in South Africa.

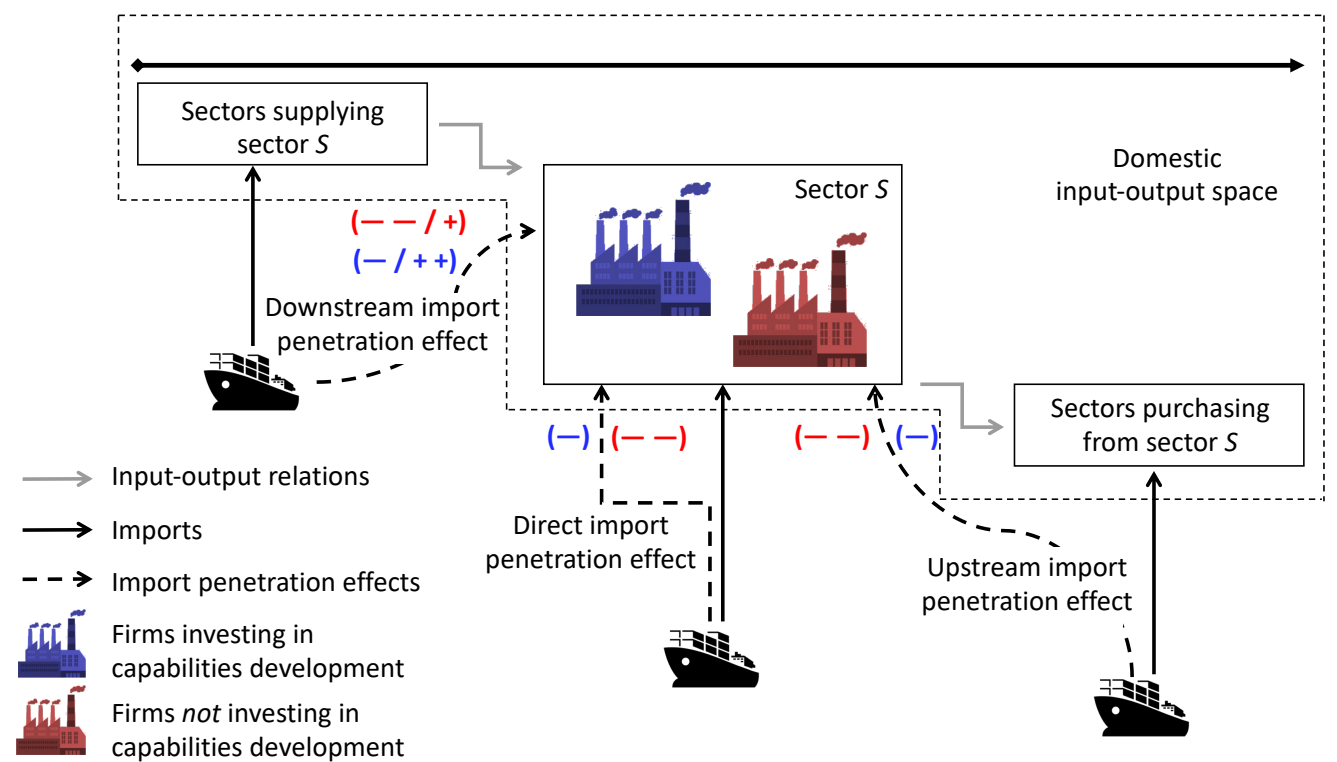

Source: authors' elaboration.

In this section, we provide details about (i) the data and the methodology used in order to construct our measures of import competition, firm-level outcomes and control variables; (ii) the empirical strategy adopted to explore the testable hypotheses formulated above.

\subsection{Data}

This empirical study uses information from three different sources. Import penetration variables-direct and indirect-are constructed using trade information provided by the UN Comtrade database, and production and input-output data made available by Statistics South Africa, while firm-level data from company and employee income tax certificates are obtained from SARS. 
Our main industry-level import penetration variable is computed as the ratio of sectoral imports from China_PEN ${ }^{c h n}$ - to apparent sector-specific consumption in each year. Analytically:

$$
P E N_{s, t}^{c h n}=\frac{M_{s, t}^{c h n}}{M_{s, t}+Y_{s, t}-X_{s, t}}
$$

where $M_{s, t}^{c h n}$ is the value of imports from China in sector $s$ in year $t ; M_{s, t}$ is the value of total imports (including China) in sector $s$ in year $t$; while $Y_{s, t}$ and $X_{s, t}$ represent the South African sectoral domestic production and exports, respectively. ${ }^{7}$

Industry-level production data are provided by the Manufacturing Sales and Production database of Statistics South Africa for 42 manufacturing sub-sectors (Statistics South Africa 2018b). ${ }^{8}$ Imports and exports data come from the UN Comtrade database (UN Comtrade 2018). Using official correspondence tables, we convert trade data at the six-digit commodity level of the World Customs Organisation Harmonized System (HS-2007) into International Standard Industrial Classification of All Economic Activities (ISIC4) manufacturing sectors. These groups are then slightly adjusted to perfectly match the industry classification adopted by Statistics South Africa.

\section{Measuring indirect import exposure}

In addition to the direct import penetration effect calculated as indicated above, our econometric analysis also takes into account the impacts of trade exposure on firm performance arising indirectly through input-output interdependencies. Following Acemoglu et al. (2016), to identify the upstream effect represented in Figure 2, we compute the following variable for each sector $s$ :

$$
P E N_{s, t}^{c h n, u p}=\sum_{k} w_{k, s, 2008}^{u p} \cdot P E N_{k, t}^{c h n}
$$

which is equal to the weighted average of import penetration faced in year $t$ by all the industries, indexed by $k$, that purchase inputs from sector $s$. These weights $-w_{k, s, 2008}^{u p}$-are defined as:

$$
w_{k, s, 2008}^{u p}=\frac{\mu_{k, s, 2008}^{u p}}{\sum_{k^{\prime}} \mu_{k^{\prime}, s, 2008}^{u p}},
$$

where $\mu_{k, s, 20008}^{u p}$ represents the value in the 2008 South African input-output table of the output of sector $s$ purchased by industry $k$, such that the weight reported in Equation 3 constitutes the proportion of total sales of industry $s$ that industry $k$ uses as inputs within its production process. We decided to use the

\footnotetext{
${ }^{7}$ As a counterfactual exercise, in order to identify the specific effect of industry-level Chinese import competition, in some specifications we also control for import penetration from other low-wage countries and the rest of the world (e.g. mainly upper-middle- and high-income economies). Such variables are computed following the formula in Equation 1, substituting the numerator with $M_{s, t}^{\text {low }}$ and $M_{s, t}^{\text {oth }}$, respectively. See Section 4.2 for further details.

${ }^{8}$ In order to ensure consistency with sectoral trade data, we aggregate 'Publishing' (324) with 'Printing and related services' (325/6) and 'Electrical motors, generators and transformers' (361) with 'Electricity distribution and control apparatus' (362). Tobacco products are excluded as sales data are not provided by Statistics South Africa.
} 
2008 input-output table rather than time-varying input-output coefficients since it pre-dates the period covered in our analysis and thus measures sectoral interdependencies that are unlikely to be endogenous to the subsequent import penetration. ${ }^{9}$ Following a similar approach, we estimate the downstream effect described in Figure 2-PEN chn, down —and experienced by each sector $s$ as the weighted average of import penetration faced in year $t$ by all the industries, indexed by $k$, from which industry $s$ buys its inputs. We use the same formula as the one reported in Equation 2 after reversing the $s$ and $k$ indexes in the numerator of Equation 3. ${ }^{10}$ The formula in Equation 2 refers to the direct (e.g. first-order) effects on a given industry $s$ arising from the import penetration exposure faced by its direct suppliers and buyers. In order to account for the full production chain of interdependent downstream and upstream linkages (e.g. the import penetration exposure faced by all suppliers' suppliers and buyers' buyers of sector $s$ ), in some additional specifications we substitute $P E N_{s, t}^{c h n, u p}$ and $P E N_{s, t}^{c h n, d o w n}$ with the entire series of implied responses from the input-output table, given by the Leontief inverse of the matrix of upstream and downstream linkages.

\section{Main firm-level outcomes and controls: tax administrative data}

The primary firm-level data source is the South African Corporate Income Tax (CIT) data, which includes firms' self-reported items with respect to income, expenditures, equity and liabilities, capital items, and tax credits. ${ }^{11}$ Starting from this source, we use employee income tax certificates (IRP5 forms) to construct a measure of labour employed by each firm. ${ }^{12}$ The data are then restricted to cover the population of manufacturing firms for the 2010-17 period. In order to systematically identify manufacturing firms, in this study we use the main industry code of the Standard Industrial Classification (SIC7), provided by the CIT database. ${ }^{13}$ These codes are then converted to the fourth revision of ISIC (ISIC4) and slightly adjusted to perfectly match the industry grouping adopted by Statistics South Africa as described in the subsection 'Measuring direct import exposure'. ${ }^{14}$ Finally, we exclude from the sample those firms with non-positive and missing employment, sales, value-added, and capital data. Our

\footnotetext{
${ }^{9}$ We decided not to use the input-output table from 2009 because in that year the effects of the global financial crisis unfolded in South Africa.

${ }^{10}$ For the purpose of this specific empirical exercise, we restrict the analysis of the impact of indirect import competition on manufacturing firms to all non-services industries. This means that all upstream and downstream effects experienced by a certain manufacturing sector emanate by definition from import exposure of their purchasers from agriculture, forestry, mining, manufacturing, utilities, and construction (e.g. $P E N_{k, t}^{c h n}$ is set equal to zero for services industries and for final demand for both downstream and upstream import penetration effects).

${ }^{11}$ For a full description of the dataset and how it is constructed and compiled, see Kreuser and Newman (2018). This paper is based on the version of the dataset available in March 2019.

${ }^{12}$ IRP5 data are aggregated for each pay-as-you-earn (PAYE) reference number.

${ }^{13}$ The two databases described above report different industry classification variables and some firms do not consistently locate themselves in a given industry within or across the different data sources. Furthermore, starting from the data release of January 2019, the main industry variable available in the CIT database and based on the raw data provided by SARS has been found to be completely unreliable. Therefore, the industry variable used in the present study has been merged from the previous version of the panel (i.e. 2010-15) into the new dataset for each firm, based on the tax reference number and the year. For 2016-17, sector codes have been allocated based on the last available observation for each firm. Although being, in our opinion, the best possible imputation procedure available, this approach does not allow us to identify industry-switchers and new entrants during the 2016-17 period.

14 With respect to industry-switchers from 2010 to 2015, we adopt the following 'cleaning' strategy. When firms change industry classifications in a single period and then revert to the original classification, we replace that period industry code with the original industry code, assuming they have never switched. When the switch in industry classification is longer than one period and continues until 2015, we assume that this reflects an actual change in industry classification. Missing industry variables are imputed using the available prior- and post-period industry codes. For the 2016-17 period we apply the imputation procedure described above.
} 
final sample covers over 16,000 firm observations for each year between 2010 and 2017, distributed over 42 manufacturing sectors. ${ }^{15}$

Using information from the resulting dataset, we construct a battery of firm-level measures of firm performance, to be used as dependent variables in the subsequent analysis. To limit endogeneity problems, we follow Bernard and Jensen (2004) and use firm covariates at time $t$ while considering dependent variables at time $t+1$. The first outcome variable used is firm employment growth $-\Delta \log (\text { Employment })_{i, t+1}-$ which is defined as the log difference between a firm's full-time equivalent total employment in year $t+1$ and $t .{ }^{16}$ The second variable is output growth- $\Delta \log (\text { Sales })_{i, t+1}$ - which is defined as the log difference between a firm's total sales in year $t+1$ and $t$. Finally, as an additional dependent variable we consider firm exit-Death $h_{i, t+1}$ - which takes a value of 1 for firms operating in $t$ but not operating in $t+1$, and 0 for firms operating in both periods. ${ }^{17}$

For dependent variables, we consider a number of covariates. First, as standard in the literature, the $\log$ of total employment $-\log (E)_{i, t}$-and the $\log$ of the number of years since registration plus $1-$ $\log (\text { Age })_{i, t}$ - are used as measures for firm size and age, respectively.

Second, we explore the richness of our dataset to identify specific firm-level variables related to investments in capabilities development, serving as indicators for the intensity of firms' process innovation, product innovation, and skills development. Unlike innovation surveys, our data source, by its very nature as an administrative dataset, does not provide any direct measure on process ${ }^{18}$ and product innovation. ${ }^{19}$ Furthermore, the IRP5 forms do not include any information on the skill levels of employees. ${ }^{20}$ Thus, in our analysis we have been forced to use indirect measures of production and technology capabilities as our main covariates of interest.

Process innovation is proxied by investment intensity-INVST $T_{i, t}$ - which is measured as the yearly additions to the firm's net assets in capital equipment (e.g. gross assets adjusted for depreciation), normalized by sales. ${ }^{21}$ Product innovation is measured as the total expenditures in innovation-related activities (e.g. a composite index obtained by the sum of $\mathrm{R} \& \mathrm{D}$ and royalties expenditures) $-I N N O V_{i, t}$ —normalized by total sales. In order to investigate in detail the relevance of spending in innovation-related activities, in some estimates we also employ as covariates two additional variables. On the one hand, as a proxy of internal product innovation, we define an indicator of firms' investment intensity in R\&D activities$R \& D_{i, t}$. On the other hand, as a proxy of external product innovation, we consider firms' investment intensity in royalties-ROYAL $L_{i, t}$. Finally, skills development is defined as the total spending in training activities-TRAIN $N_{i, t}$ - normalized by total sales. ${ }^{22}$ Using industry-level price deflators provided by Statistics South Africa, all monetary variables are translated into constant 2012 rand. Table A1 in the Appendix reports summary statistics for the sample of South Africa-based manufacturing firms over the 2010-17 period that we use in our empirical analysis.

\footnotetext{
${ }^{15}$ Due to the absence of sectoral output data on tobacco products, as outlined in the subsection 'Measuring direct import exposure', we ignore firms operating in this industry.

${ }^{16}$ We refer to this variable as full-time equivalent employment because in calculating the total number of employees by firm, each employee is weighted by the total number of periods she or he has actually worked at that company.

${ }^{17}$ For firms that exit and enter the dataset many times, we consider as shutdown year only the one of their final appearance.

${ }^{18}$ Such as, for example, unit cost reduction and sales increases due to quality improvements resulting from process innovation.

${ }^{19}$ Such as, for example, the share of sales resulting from product innovation.

${ }^{20}$ Such as, for example, years of schooling, level and type of degree awarded, specific functions performed within the firm.

${ }^{21}$ In order to compute such a variable, we use the assets in property, plant, and equipment, which identify the maximum level of disaggregation with respect to capital equipment included in the ITR14 form.

${ }^{22}$ In some unreported alternative specifications (available upon request), we normalize the spending in training activities by total full-time equivalent employment, getting very similar regression results.
} 


\subsection{Empirical strategy}

The basic idea of the present analysis is to study a number of margins of adjustments to Chinese import penetration of manufacturing firms in South Africa, controlling for firm heterogeneity in terms of investment in capability development activities. On the one hand, we examine whether Chinese competition has generated a negative impact on manufacturing firms, either affecting their employment decisions, their output dynamics, or their probability of closing down. On the other hand, we explore to what extent firms investing in process and product innovation and skills development are more resilient to Chinese competition with respect to the outcome variables stated above. These outcomes between $t$ and $t+1$ are related to a set of year $t$ firm characteristics, $V_{i, t}$, the sectoral Chinese import penetration-either direct or indirect-in year $t$, and a set of interactions - $X_{i, s, t}$ - between such trade exposure variables and firm-level capabilities (e.g. capital investment, innovation, and training dummies): ${ }^{23}$

$$
\text { Outcome }_{i}^{t, t+1}=f\left(V_{i, t}, P E N_{s, t}^{c h n}, X_{i, s, t}\right) .
$$

The introduction of interactions allows us to analyse the impact of import competition across firms within an industry, taking into account firm-level heterogeneity in terms of production and technology capabilities. More specifically, we consider three different firm outcomes. The first set of results examines the influence of Chinese imports on employment growth of surviving firms:

$$
\Delta \log (\text { Employment })_{i}^{t, t+1}=c+V_{i, t}^{\prime} \alpha+P E N_{s, t}^{\prime c h n} \beta+X_{i, s, t}^{\prime} \gamma+\delta_{t}+\delta_{i}+\varepsilon_{i, t}
$$

Our set of firm characteristics encompasses log total employment, log age, intensity in capital investments, innovation activities, and skills development as defined in the subsection 'Main firm-level outcomes and controls: tax administrative data'. Second, we explore to what extent Chinese import penetration impacts sales growth of surviving firms:

$$
\Delta \log (\text { Sales })_{i}^{t, t+1}=c+V_{i, t}^{\prime} \alpha+P E N_{s, t}^{\prime c h n} \beta+X_{i, s, t}^{\prime} \gamma+\delta_{t}+\delta_{i}+\varepsilon_{i, t} .
$$

The third adjustment margin analysed is the potential demise of domestic manufacturing firms:

$$
\operatorname{Pr}(\text { Death }=1)_{i}^{t, t+1}=c+V_{i, t}^{\prime} \alpha+P E N_{s, t}^{\prime c h n} \beta+X_{i, s, t}^{\prime} \gamma+\delta_{t}+\delta_{i}+\varepsilon_{i, t},
$$

where $\delta_{t}$ and $\delta_{i}$ represent time and firm fixed effects, respectively. Regressions 6 and 7 employ the same firm characteristics and interaction variables as the employment growth specification in Equation 5. Following Alvarez and Claro (2009) and Mion and Zhu (2013), we use a linear probability model as our main specification for regression 7, and not more conventional discrete choice models as probit or logit, to allow for firm-specific effects that may affect probability of exit.

In order to identify the specific effect of Chinese import competition, which constitutes our main variable of interest, in some estimates we also control for import competition from the rest of the world $\left(P E N^{\text {oth }}\right)$, and other low-wage countries $\left(P E N^{l o w}\right)$, defined as economies with per-capita income lower

\footnotetext{
${ }^{23}$ In this version of the paper we report and interpret only estimates including interaction terms between our trade exposure variables and a battery of dummies taking the value 1 if the firm in year $t$ invests in capital equipment, innovation-related activities, and training programs.
} 
that 15 per cent of the US per capita income. ${ }^{24}$ Finally, we also replicate all our estimates including a set of province dummy variables to control for potential shocks to specific locations over time. In all subsequent estimates, following Cameron et al. (2011), we employ a two-way (firm and industry) clustering approach to correct for unobservable firm- and sector-specific shocks uncorrelated with both $\varepsilon_{i, t}$ and our independent variables.

\section{Instrumenting Chinese import penetration}

One concern about Equation 1 as a measure of trade exposure in our subsequent estimations is that observed dynamics in import penetration ratio may in part reflect domestic shocks to South African industries that affect their import demand. In this case the OLS (ordinary least squares) estimate of how imports from China affect the performance of manufacturing firms in South Africa might lead to biased results of the Chinese import penetration coefficient.

In order to address this problem and to identify the causal effect of rising Chinese import exposure on the performance of manufacturing firms in South Africa, we employ an instrumental variable approach that accounts for the potential endogeneity of trade exposure. More specifically, we instrument Chinese import penetration with China's share of imports in other low- and middle-income countries (excluding South Africa). ${ }^{25}$ Analytically:

$$
P E N_{s, t}^{l m i c, c h n}=\frac{M_{s, t}^{l m i c, c h n}}{M_{s, t}^{l m i c, w l d}},
$$

where $M_{s, t}^{l m i c, c h n}$ is the value of Chinese imports into low- and middle-income countries (excluding South Africa) and $M_{s, t}^{l m i c, w l d}$ is the value of their total imports in sector $s$ in year $t$. The motivation for using this instrument is that other low- and middle-income economies are similarly exposed to imports pressure from China that is driven by supply shocks in the country. Indeed, over 2010-17, the share of total manufacturing imports accounted for by China increased from 17 per cent to over 22 per cent in South Africa, and from over 14 per cent to more than 18 per cent in other low- and middle-income countries. ${ }^{26}$ The first-stage regression (Figure A1 in the Appendix), with time fixed effects and without detailed

\footnotetext{
${ }^{24}$ Bernard et al. (2006) and Alvarez and Claro (2009) employ a lower income threshold (5 per cent of the US per-capita income). However their studies are restricted to the pre-2000 period when China's per-capita GDP was below the threshold of 5 per cent, increasing from 1.4 per cent of the US per-capita GDP in 1990 to 3.6 per cent in 2000. Since our analysis focuses on the 2010-17 period, we raise the income threshold in order to make a more accurate comparison with other lowand middle-income countries, taking into account the enormous progress on the economic and living standards side made by China during the last two decades. During our period of interest, China's per-capita GDP was below the threshold of 15 per cent, increasing from 9.4 per cent of the US per-capita GDP in 2010 to 13.8 per cent in 2017. Table A2 in the Appendix provides a list of the countries that are classified as low-wage countries in all years of the sample (excluding China). It includes emerging economies such as India, Indonesia, Thailand, and Viet Nam, as well as relatively small exporters such as many small island developing states (SIDS).

${ }^{25}$ Edwards and Jenkins (2015) employ this instrument to analyse the contribution of Chinese import penetration to rising labour productivity at the sectoral level for 44 South African manufacturing industries. A similar instrumental approach is followed by Iacovone et al. (2013) to examine the impact of Chinese competition on Mexican manufacturing firms. We classify countries as low- and middle-income countries using the World Bank definition from 2010.

${ }^{26}$ In 2017, imports from China accounted for over 50 per cent and 40 per cent of total manufacturing imports from developing economies in South Africa and in other low- and middle-income countries, respectively.
} 
controls, confirms the strong predictive power of China's share of imports in other low- and middleincome countries for Chinese import penetration in South Africa. ${ }^{27}$

Our identification strategy is inspired by Autor et al. (2013), who consider the relationship between imports from China and local labour market effects in the United States. As suggested by Autor et al. (2013), we exploit the fact that much of the growth in Chinese exports during the last three decades, including our main period of interest, appears to be strongly related to factors that are specific to China. The historical evidence suggests that the impressive increase in the country's absolute and relative manufacturing capacity and competitiveness has been driven by massive productivity growth and extensive policy reforms (e.g. a supply shock from the South African and other developing countries' producer perspective). ${ }^{28}$

\section{$5 \quad$ Descriptive analysis}

In this section, we present some preliminary statistics and highlight (1) the key trends of Chinese competitive pressure in South African manufacturing in the aftermath of the global financial crisis, and (2) the main traits of the population of South Africa-based manufacturing firms, focusing on patterns of investments in capabilities.

\subsection{Chinese import competition in the South African manufacturing sector}

Table 1 reports the share of China in total South African imports and total domestic consumption for 42 manufacturing industries in 2010 and 2017. Sectors are grouped by technological categories on the basis of the classification proposed by Lall (2000) specifically for developing countries and reported in Table A3 in the Appendix. ${ }^{29}$

While China still represents a major source of imports in the traditional low-technology and labourintensive sectors such as textiles, clothing, and footwear, during the 2010-17 period its dominance had also shifted to medium- to high-technology electronic and machinery sectors. For example, in 2017 China accounted for over 30 per cent of total South African imports of non-metallic mineral and glass products, furniture, textiles products (knitted and crocheted fabrics, clothing, leather and leather products, footwear), consumer electronics (household appliances, electrical lamps, wires and cables, accumulators and batteries, TV, radios, and communication apparatus), the bulk of the metals, machinery, and equipment value chain products (basic iron and steel, structural steel and fabricated metal products, and general purpose machinery), and bodies of motor vehicles (see the second column in Table 1 and Figure 3).

\footnotetext{
${ }^{27}$ Analogously to our main import penetration measures, upstream and downstream exposure variables are instrumented by replacing the term $P E N_{k, t}^{c h n}$ with $P E N_{k, t}^{l m i c, c h n}$ in Equation 2 while retaining the same weights.

${ }^{28}$ The potential shortcomings of our identification strategy are presented in Section A1.1 in the Appendix.

${ }^{29}$ We believe that this classification is better suited to a country such as South Africa than the one proposed by Hatzichronoglou (1997) and used by the OECD, which is based on direct R\&D intensity and R\&D embodied in intermediate and investment goods in a subset of advanced countries. Unfortunately, due to the specific industry classification used, we are not able to distinguish between medium- and high-technology sectors, thus we construct a single category for both.
} 
Table 1: Percentage of China's imports in total South African imports and domestic consumption, $2010-17$.

\begin{tabular}{|c|c|c|c|c|c|}
\hline \multirow[b]{2}{*}{ Code } & \multirow[b]{2}{*}{ Description } & \multicolumn{2}{|c|}{$\begin{array}{l}\text { Percentage of China } \\
\text { in total SA imports }\end{array}$} & \multicolumn{2}{|c|}{$\begin{array}{c}\text { Percentage of Chinese } \\
\text { import penetration }\end{array}$} \\
\hline & & 2010 & 2017 & 2010 & 2017 \\
\hline & Resource-based & & & & \\
\hline 301 & Meat, fish, fruit, etc. & 3.19 & 5.77 & 0.79 & 1.18 \\
\hline 302 & Dairy products & 0.79 & 0.94 & 0.04 & 0.06 \\
\hline 303 & Grain mill prod., animal feeds & 3.79 & 3.79 & 0.38 & 0.53 \\
\hline 304 & Other food products & 2.60 & 2.20 & 0.24 & 0.30 \\
\hline 305 & Beverages & 0.17 & 0.24 & 0.01 & 0.01 \\
\hline 321 & Sawmilling, planing of wood & 4.63 & 2.96 & 0.85 & 0.57 \\
\hline 322 & Wood, wood products & 24.11 & 25.61 & 2.12 & 3.27 \\
\hline 323 & Paper, paper products & 8.30 & 12.80 & 1.37 & 2.74 \\
\hline $331 / 2$ & Coke oven, petroleum products & 2.81 & 4.22 & 0.85 & 1.62 \\
\hline 337 & Rubber products & 23.03 & 26.97 & 10.78 & 15.00 \\
\hline 341 & Glass, glass products & 37.76 & 37.91 & 8.38 & 10.28 \\
\hline \multirow[t]{2}{*}{342} & Non-metallic mineral products & 24.79 & 31.98 & 3.61 & 5.79 \\
\hline & Low-tech & & & & \\
\hline 311 & Spinning, weaving of textiles & 42.48 & 45.73 & 18.50 & 24.42 \\
\hline 312 & Other textiles & 36.96 & 36.47 & 8.23 & 15.52 \\
\hline 313 & Knitted, crocheted fabrics & 58.20 & 52.76 & 31.50 & 44.69 \\
\hline $314 / 5$ & Clothing & 61.52 & 58.94 & 25.56 & 29.69 \\
\hline 316 & Leather, leather products & 47.75 & 58.07 & 18.56 & 29.69 \\
\hline 317 & Footwear & 73.79 & 60.98 & 48.94 & 47.63 \\
\hline $324 / 5 / 6$ & Publishing, printing, rel. serv. & 18.48 & 13.92 & 1.30 & 1.91 \\
\hline 354 & Structural steel products & 12.92 & 30.56 & 0.86 & 2.02 \\
\hline 355 & Other fabricated metal products & 31.74 & 37.59 & 6.43 & 9.02 \\
\hline 391 & Furniture & 47.52 & 45.08 & 18.23 & 15.39 \\
\hline \multirow[t]{2}{*}{392} & Other manufacturing & 47.81 & 43.15 & 7.74 & 8.89 \\
\hline & Medium- to high-tech & & & & \\
\hline 334 & Basic chemicals & 11.31 & 18.82 & 5.09 & 9.71 \\
\hline $335 / 6$ & Other chemicals & 6.11 & 7.57 & 2.47 & 3.51 \\
\hline 338 & Plastic products & 21.69 & 25.31 & 3.25 & 5.88 \\
\hline 351 & Basic iron, steel & 16.26 & 31.11 & 3.38 & 7.75 \\
\hline 352 & Non-ferrous metals & 9.22 & 13.18 & 2.32 & 3.40 \\
\hline $356 / 9$ & General-purpose machinery & 25.62 & 37.36 & 23.83 & 39.96 \\
\hline 357 & Special-purpose machinery & 10.92 & 18.51 & 6.20 & 11.25 \\
\hline 358 & Household appliance & 61.62 & 62.79 & 21.21 & 25.41 \\
\hline $361 / 2$ & Electrical equip., apparatus & 17.60 & 28.50 & 9.52 & 19.56 \\
\hline 363 & Insulated wire, cable & 23.65 & 37.13 & 4.40 & 9.58 \\
\hline 364 & Accumulators, batteries & 27.62 & 43.40 & 11.44 & 23.99 \\
\hline 365 & Electric lamps, lighting equip. & 59.10 & 64.94 & 31.33 & 37.80 \\
\hline 366 & Other electrical equipment & 16.82 & 26.46 & 4.43 & 11.03 \\
\hline $371 / 2 / 3$ & TV, radio, other electronic equip. & 35.67 & 66.42 & 30.95 & 51.14 \\
\hline $374 / 5 / 6$ & Medical, measuring, controlling equip. & 9.51 & 14.86 & 7.88 & 14.10 \\
\hline 381 & Motor vehicles & 2.97 & 1.64 & 1.48 & 1.02 \\
\hline 382 & Bodies for motor vehicles & 32.06 & 30.12 & 3.47 & 5.24 \\
\hline 383 & Parts, accessories for motor vehicles & 8.53 & 13.33 & 1.61 & 3.04 \\
\hline $384 / 5 / 6 / 7$ & Other transport equipment & 3.20 & 10.38 & 1.38 & 5.10 \\
\hline- & Total & 17.77 & 22.47 & 5.26 & 8.30 \\
\hline
\end{tabular}

Source: authors' calculations using UN Comtrade (2018) and Statistics South Africa (2018b) data. 
Figure 3: Levels and changes in Chinese import penetration, 2010-17.
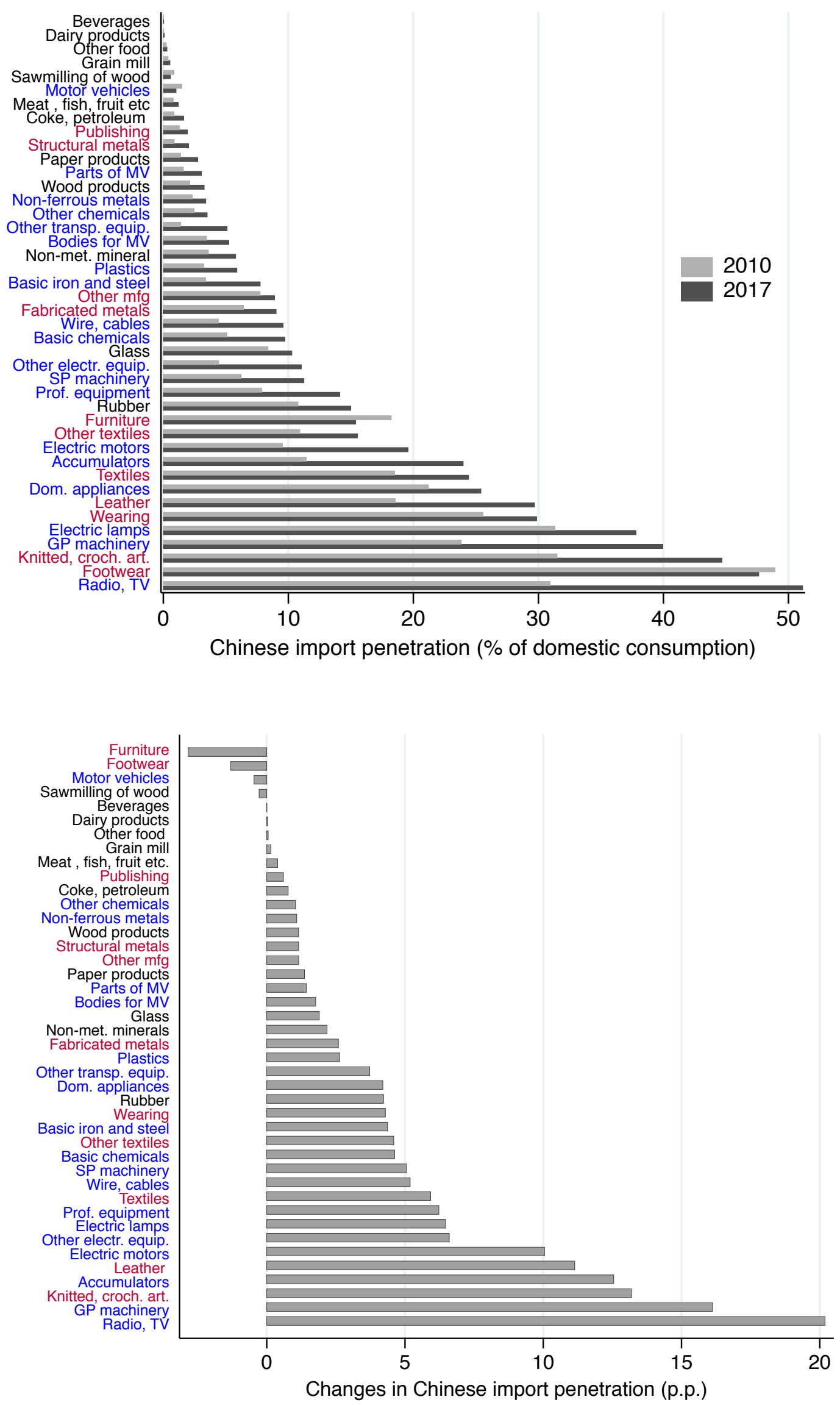

Notes: colours represent resource-based (black), low-tech (red), and medium- to high-tech (blue) sectors, respectively. Source: authors' calculations using UN Comtrade (2018) and Statistics South Africa (2018b). 
The extent of the impact of imports from China across manufacturing industries is also reflected in the rising share of these goods in domestic consumption. Looking across the sectors, all manufacturing industries but 'Sawmilling and planing of wood' (321), 'Footwear' (317), 'Furniture' (391), and 'Motor vehicles' (381) experienced increases in Chinese import penetration ratios between 2010 and 2017 (see the last two columns in Table 1 and Figure 3). There are, however, significant differences across industries in the level and change in import penetration by China over this period. These are smallest (less than 1 percentage point increase from 2010 to 2017) in some agricultural and resource-based products (beverages; dairy products; other food products; coke and petroleum; publishing, printing, and related services; meat, fish, fruit, vegetables, oils, and fat). In contrast, large increases in the share of imports from China in domestic consumption are recorded from 2010 to 2017 in television, radio, and other communication apparatus (20.19 percentage points); general-purpose machinery (16.13 percentage points); knitted and crocheted fabrics (13.19 percentage points); accumulators and batteries (12.55 percentage points); leather products (11.14 percentage points); and electric motors, generators, and transformers (10.05 percentage points).

Furthermore, the comparison between Chinese and other low-wage countries' import penetration over the period 2010-17 (see Table 2) qualifies China as special in the pool of low-income economies. Indeed, the level of China's share in South African apparent consumption for most medium- to high-technology products, such as general- and special-purpose machinery and electronics, is significantly higher than import penetrations from other low-wage economies (the main exceptions are other chemicals and motor vehicles). ${ }^{30}$ The negligible relevance of imports from other low-wage countries in such sectors also contrasts with the magnitude observed in import penetration from the rest of the world (e.g. mainly upper-middle- and high-income countries). This evidence might suggest the existence of two relatively distinct market segments: the first being one mostly monopolized by the presumably cheaper, less sophisticated and more standardized Chinese products, and the second one dominated by the high-end goods manufactured by advanced economies (e.g. Germany, Japan, the United States, Italy, and Korea). Nonetheless, in some such sectors, import penetration from the rest of the world has decreased between 2010 and 2017 (e.g. by 23.38 percentage points for TV, radio, and other communication apparatus, and by 9.30 and 2.99 percentage points for general- and special-purpose machinery, respectively). This evidence suggests that in such industries the increase in Chinese import penetration has come also at the expense of imports from other countries, especially upper-middle- and high-income ones.

\footnotetext{
${ }^{30}$ In many electronics sectors, even the growth rate of Chinese import penetration exceeds that of other low-wage countries.
} 
Table 2: Percentage of imports in total South African domestic consumption by origin, 2010-17.

\begin{tabular}{|c|c|c|c|c|c|c|c|}
\hline \multirow[b]{3}{*}{ Code } & \multirow[b]{3}{*}{ Description } & \multicolumn{6}{|c|}{ Other } \\
\hline & & \multicolumn{2}{|c|}{ China } & \multicolumn{2}{|c|}{ low } & \multicolumn{2}{|c|}{ RoW } \\
\hline & & 2010 & 2017 & 2010 & 2017 & 2010 & 2017 \\
\hline & Resource-based & & & & & & \\
\hline 301 & Meat, fish, fruit, etc. & 0.79 & 1.18 & 5.99 & 5.59 & 14.02 & 13.71 \\
\hline 302 & Dairy products & 0.04 & 0.06 & 0.12 & 0.17 & 3.98 & 6.34 \\
\hline 303 & Grain mill prod., animal feeds & 0.38 & 0.53 & 7.27 & 9.47 & 2.36 & 4.05 \\
\hline 304 & Other food products & 0.24 & 0.30 & 3.92 & 4.63 & 5.22 & 8.59 \\
\hline 305 & Beverages & 0.01 & 0.01 & 1.29 & 0.70 & 4.29 & 4.91 \\
\hline 321 & Sawmilling, planing of wood & 0.85 & 0.57 & 5.89 & 10.45 & 11.58 & 8.32 \\
\hline 322 & Wood, wood products & 2.12 & 3.27 & 1.20 & 2.03 & 5.47 & 7.46 \\
\hline 323 & Paper, paper products & 1.37 & 2.74 & 1.97 & 1.75 & 13.21 & 16.90 \\
\hline $331 / 2$ & Coke oven, petroleum products & 0.85 & 1.62 & 7.40 & 9.08 & 22.00 & 27.74 \\
\hline 337 & Rubber products & 10.78 & 15.00 & 3.94 & 6.32 & 32.07 & 34.31 \\
\hline 341 & Glass, glass products & 8.38 & 10.28 & 2.27 & 2.20 & 11.55 & 14.64 \\
\hline \multirow[t]{2}{*}{342} & Non-metallic mineral products & 3.61 & 5.79 & 0.92 & 1.54 & 10.03 & 10.76 \\
\hline & Low-tech & & & & & & \\
\hline 311 & Spinning, weaving of textiles & 18.50 & 24.42 & 14.47 & 19.54 & 10.57 & 9.45 \\
\hline 312 & Other textiles & 10.93 & 15.52 & 6.43 & 10.46 & 12.21 & 16.57 \\
\hline 313 & Knitted, crocheted fabrics & 31.50 & 44.69 & 9.91 & 26.28 & 12.71 & 13.73 \\
\hline $314 / 5$ & Clothing & 25.56 & 29.85 & 8.82 & 21.23 & 7.16 & 5.87 \\
\hline 316 & Leather, leather products & 18.56 & 29.70 & 6.50 & 9.89 & 13.81 & 10.79 \\
\hline 317 & Footwear & 48.93 & 47.63 & 12.13 & 24.17 & 5.24 & 6.31 \\
\hline $324 / 5 / 6$ & Publishing, printing, rel. serv. & 1.30 & 1.91 & 0.55 & 2.11 & 5.20 & 9.69 \\
\hline 354 & Structural steel products & 0.86 & 2.02 & 0.67 & 0.87 & 5.15 & 3.71 \\
\hline 355 & Other fabricated metal products & 6.43 & 9.02 & 2.05 & 2.42 & 11.78 & 12.56 \\
\hline 391 & Furniture & 18.23 & 15.39 & 4.52 & 5.15 & 15.60 & 13.61 \\
\hline \multirow[t]{2}{*}{392} & Other manufacturing & 7.74 & 8.89 & 2.10 & 3.72 & 6.33 & 7.99 \\
\hline & Medium- to high-tech & & & & & & \\
\hline 334 & Basic chemicals & 5.09 & 9.71 & 7.65 & 5.58 & 32.24 & 35.32 \\
\hline $335 / 6$ & Other chemicals & 2.47 & 3.51 & 4.48 & 9.48 & 33.53 & 33.39 \\
\hline 338 & Plastic products & 3.25 & 5.88 & 1.96 & 2.31 & 9.77 & 15.05 \\
\hline 351 & Basic iron, steel & 3.38 & 7.75 & 2.39 & 2.90 & 15.03 & 14.27 \\
\hline 352 & Non-ferrous metals & 2.32 & 3.40 & 4.16 & 4.20 & 18.67 & 18.22 \\
\hline $356 / 9$ & General-purpose machinery & 23.83 & 39.96 & 3.50 & 10.61 & 65.69 & 56.39 \\
\hline 357 & Special-purpose machinery & 6.20 & 11.25 & 1.95 & 3.87 & 48.66 & 45.67 \\
\hline 358 & Household appliance & 21.21 & 25.41 & 1.96 & 1.90 & 11.24 & 13.16 \\
\hline $361 / 2$ & Electrical equip., apparatus & 9.52 & 19.56 & 4.10 & 4.32 & 40.46 & 44.77 \\
\hline 363 & Insulated wire, cable & 4.39 & 9.58 & 3.53 & 2.12 & 10.67 & 14.10 \\
\hline 364 & Accumulators, batteries & 11.44 & 23.99 & 1.96 & 3.57 & 28.01 & 27.72 \\
\hline 365 & Electric lamps, lighting equip. & 31.33 & 37.80 & 2.69 & 2.38 & 18.99 & 18.03 \\
\hline 366 & Other electrical equipment & 4.43 & 11.03 & 3.27 & 9.33 & 18.63 & 21.33 \\
\hline $371 / 2 / 3$ & TV, radio, other electronic equip. & 30.95 & 51.14 & 15.90 & 9.32 & 39.91 & 16.53 \\
\hline $374 / 5 / 6$ & Medical, measuring, controlling equip. & 7.88 & 14.10 & 2.48 & 3.77 & 72.45 & 76.98 \\
\hline 381 & Motor vehicles & 1.49 & 1.02 & 4.91 & 12.56 & 43.61 & 48.74 \\
\hline 382 & Bodies for motor vehicles & 3.47 & 5.24 & 0.26 & 0.77 & 7.08 & 11.38 \\
\hline 383 & Parts, accessories for motor vehicles & 1.61 & 3.04 & 1.23 & 2.21 & 15.99 & 17.53 \\
\hline $384 / 5 / 6 / 7$ & Other transport equipment & 1.38 & 5.10 & 0.58 & 0.91 & 41.18 & 43.16 \\
\hline- & Total & 5.26 & 8.30 & 4.32 & 6.56 & 23.45 & 25.08 \\
\hline
\end{tabular}

Source: authors' calculations using UN Comtrade (2018) and Statistics South Africa (2018b) data. 
The evidence presented in Tables 1 and 2, and in Figure 3 captures the structural transition of China increasingly specializing in the export of medium- to high-tech products and some industrial raw materials (e.g. steel) to South Africa. As already underlined by Rodrik (2006) and Schott et al. (2008), Chinese exports seem to be more sophisticated and to show more overlap with OECD countries' products compared to other low-wage economies. However, one might point out that the huge quantities of Chinese exports in medium- to high-technology products, such as electronics, should not be interpreted as evidence per se that Chinese firms are able to compete in skill-intensive high-technology sectors. For example, Branstetter and Lardy (2006) argue that most of the exported electronics and information technologies are not manufactured by Chinese firms, but by foreign firms that use China merely as a parts assembler and exports platform within GVCs. Although this might still have been the case in the early 2000s when Branstetter and Lardy were writing, it has now become clear that, during the last two decades, China has upgraded its position within GVCs towards higher value-added activities (Tassey 2014; Zhou et al. 2016).

Figure 4 shows that the domestic value-added (DVA) of Chinese exports, both to the world and specifically to South Africa, has experienced constant growth since $2005 .{ }^{31}$ Figure 4 reports data on total manufacturing and selected medium- to high-tech manufacturing sub-sectors. In 2005, for example, around 40 per cent of the value of machinery and equipment exports, both to the world more widely and to South Africa, consisted of foreign content, but by 2016 this had dropped to less than 28 per cent, with similar declines observed in other medium- to high-tech manufacturing sectors.

Figure 4: Trends in Chinese domestic value-added content of exports by manufacturing sector, 2005-16.
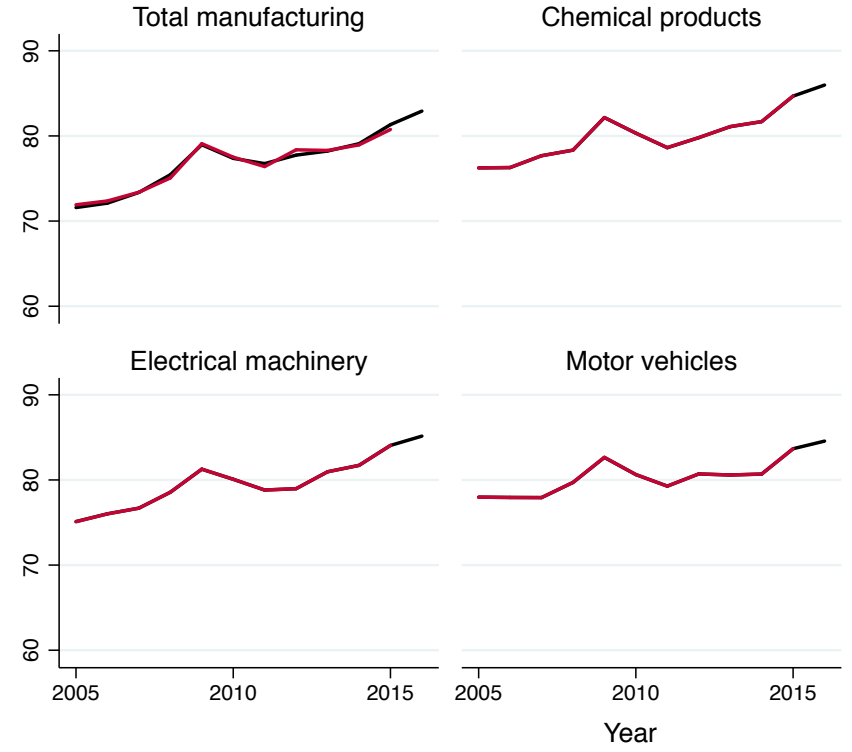

Chinese DVA in global exports (\% of gross exports) Chinese DVA in exports to South Africa (\% of gross exports)

Notes: Chinese domestic value-added content of global exports as a percentage of global gross exports between 2005 and 2016 (black line); Chinese domestic value-added content of exports to South Africa as a percentage of gross exports to South Africa between 2005 and 2015 (red line). Bilateral data are not available after 2015.

Source: authors' calculations using OECD-TiVA (2018).

\footnotetext{
${ }^{31}$ DVA performance reflects the extent to which a country has been able to build up its industrial capabilities and take advantage of the opportunities offered by forward integration into GVCs. Foreign value-added content of exports is defined as $1-D V A$.
} 
The evidence presented in Tables 1 and 2 and in Figures 3 and 4 reflects the twofold nature of the evolution of Chinese exports to South Africa. On the one hand, while China still represents a major source of imports for South Africa in the traditional low-technology sectors, more recently its dominance has also shifted to medium- to high-technology manufacturing sectors. On the other hand, this shift has been accompanied by an upgrading towards higher domestic value-added embodied in the exports of medium- to high-technology manufacturing products.

The dramatic technological upgrading of Chinese firms and their increasing value-addition capabilities has changed the nature of Chinese competitive pressure on firms in low- and middle-income countries. The transition of Chinese firms from exporting low-technology products (e.g. textiles) to exporting medium-to high-technology products (e.g. machine tools), and from assemblers to producers and integrators of components, might have reduced the room for manoeuvre of firms in countries like South Africa to upgrade and compete in more technologically sophisticated segments of GVCs. This conjecture is supported by the recent declining trends of domestic value-added of South African exports. Indeed, Figure 5 shows that between 2005 and 2015 South Africa experienced an erosion of domestic value-added embodied in exports of selected medium- to high-technology manufacturing sectors.

Figure 5: Trends in South African domestic value-added content of exports by manufacturing sector, 2005-15.

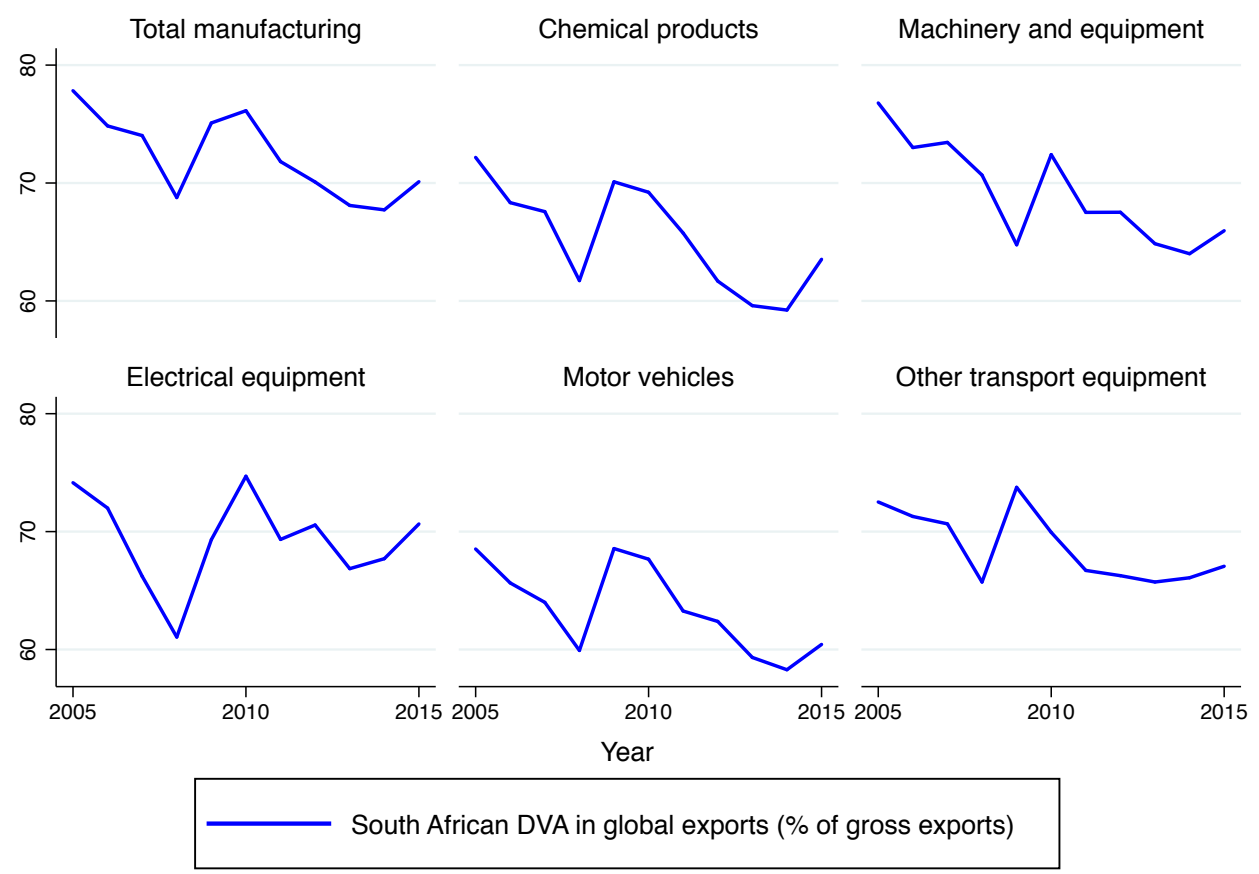

Notes: South African domestic value-added content of global exports as a percentage of global gross exports between 2005 and 2015. Data are not available after 2015.

Source: authors' calculations using OECD-TiVA (2018).

\subsection{Performances and capabilities: a portrait of South African manufacturing firms}

On average, for the 2010-17 period, approximately 64 per cent of manufacturing firms registered in South Africa report positive investment in capital equipment, while 10 per cent spend on training, and only 6 per cent invest in innovation-related activities (i.e. 4 per cent in royalties and only 2 per cent in R\&D). In terms of intensity, during the same period manufacturing firms have spent on average around 5 per cent of their total turnover on capital investment, and only 0.08 per cent and 0.13 per cent on training- and innovation-related activities, respectively (i.e. 0.09 per cent on royalties and 0.04 per cent 
on R\&D). ${ }^{32}$ However, as we would expect, there is a high degree of heterogeneity among firms of different sizes and belonging to different sectors in terms of both the average share of firms' spending in such activities and assets and the average intensity of these investments. Indeed, as shown in Table A5 in the Appendix, firms in resource-based and medium- and high-technology sectors outperform investments in capabilities development of low-technology firms, especially with respect to innovation and training efforts, both in terms of average share of investors and average intensity of spending. Similarly, as reported in Table A6 in the Appendix, more of the medium and especially large firms spend greater shares of their turnover on innovation- and training-related expenditures when compared to smaller firms.

Table 3 reports suggestive evidence of the superior performance of firms investing in one or more activities related to capabilities development when compared to firms not investing in any of these during the 2010-17 period. ${ }^{33}$ According to the evidence shown in Table 3, the average employment growth, sales growth, and survival rate of manufacturing firms investing in capabilities development activities have been substantially larger ( 19.55 per cent, 11.77 per cent, and 98.63 per cent) than that experienced by firms not undertaking any capabilities development investment (6.62 per cent, -7.79 per cent, and 94.07 per cent).

Table 3: Performance of firms investing in capabilities development versus non-investing.

\begin{tabular}{llc}
\hline Variable & Class of firms & $2010-17(\%)$ \\
\hline Average employment growth & All firms & 15.55 \\
& Firms not investing in capabilities development & 6.62 \\
& Firms investing in capabilities development & 19.55 \\
\hline Average sales growth & All firms & 5.39 \\
& Firms not investing in capabilities development & -7.79 \\
& Firms investing in capabilities development & 11.77 \\
\hline Average exit rate & All firms & 3.14 \\
& Firms not investing in capabilities development & 5.93 \\
& Firms investing in capabilities development & 1.37 \\
\hline
\end{tabular}

Source: authors' calculations using SARS data.

To start shedding some light on the relationship between growing import competition from China and the degree of capability intensity of manufacturing firms, in Figure 6 we plot the change in import penetration during the $2010-16$ period $^{34}$ against the average sectoral intensities in investment in capital equipment and innovation expenditures in 2010, for our 42 manufacturing industries. ${ }^{35}$ The pattern of stronger import penetration in less capital investment-intensive sectors seems to be confirmed by the data. Indeed, the sectors that have experienced higher growth rates in Chinese import penetration include industries that have shown relatively low levels of capital investments in 2010, such as leather and leather products, general-purpose machinery, electric lamps and lighting equipment, and TV, radio, and other electronic equipment. As expected, Chinese import competition has shown negligible or null growth rates in resource-based capital investment-intensive sectors such as non-metallic mineral products, sawmilling and planing of wood, and beverages. In the case of innovation intensity, instead, we

\footnotetext{
32 Previous research also found that R\&D intensity in South African manufacturing firms is considerably lower than that observed in studies of other countries (Steenkamp et al. 2018).

${ }^{33}$ In Table 3, the firms investing in capabilities development are firms reporting positive expenditures in year $t$ in any of the following: capital investments, $R \& D$, royalties, training.

${ }^{34}$ For the purpose of the specific descriptive in Figure 6, 2016 has been used as the final year since our subsequent econometric analysis will employ import penetration data lagged by one period. See Section 4.2 for a full description of our empirical strategy.

${ }^{35}$ Figure $\mathrm{A} 2$ in the Appendix, plotting the change in import penetration against the average sectoral intensities in training expenditures at the beginning of the period of interest, shows a very similar negative relation, although extremely weak. According to the SARS data, indeed, South Africa-based manufacturing companies did not make considerable investments in training activities in 2010 .
} 
find a weaker negative relation, suggesting that larger increases in imports from China are only slightly concentrated in industries with lower levels of innovation-related spending, such as knitted and crocheted fabrics, leather and leather products, and electric lamps and lighting equipment. More innovation investment-intensive sectors such as professional equipment, other chemicals (especially pharmaceuticals), and beverages seem to be less affected by import competition from China. Interestingly enough, the pattern of sectoral innovation intensity emerging from the analysis of the firm-level data seems to be sufficiently in line with the technological categories developed by Lall (2000), with the exception of general-purpose machinery, plastic products, basic iron and steel, and consumer electronics sectors (e.g. accumulators and batteries, electric lamps and lighting equipment, domestic appliances), which display extremely low levels of innovation intensity. ${ }^{36}$

\footnotetext{
${ }^{36}$ According to the SARS data, consumer electronics sectors are also among the most labour-intensive ones in South Africa. This evidence, besides the very low levels of investment and innovation intensity registered, suggests that manufacturing of consumer electronics in South Africa is limited to assembly of components, with minimal domestic value-addition. Thus, while informative, the industry classification proposed by Lall (2000) should be applied and interpreted with caution in the various national contexts.
} 
Figure 6: Change in Chinese import penetration over 2010-16 and average sectoral capability intensity in 2010.
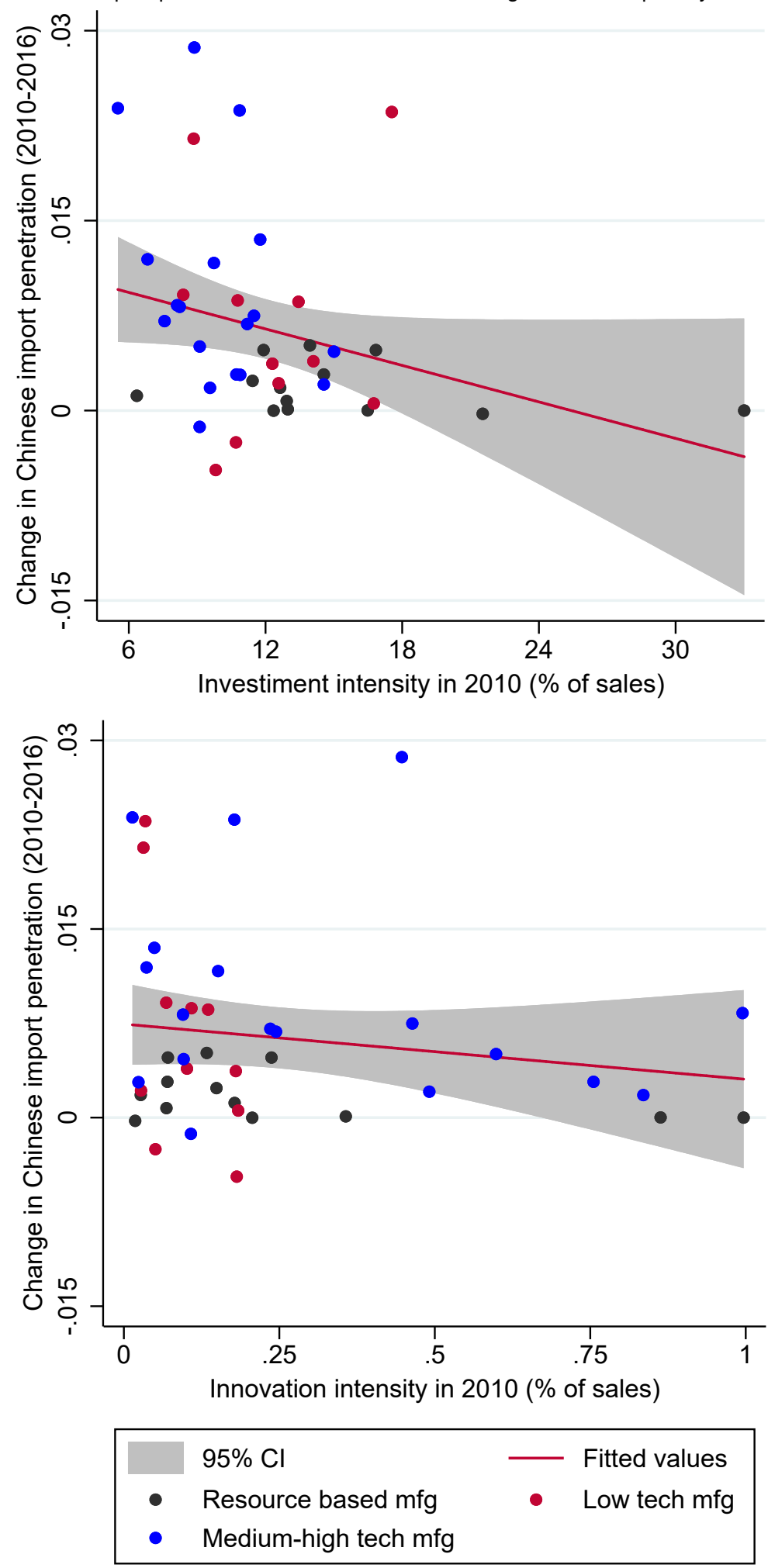

Notes: each point represents a manufacturing industry $(N=42)$. The change in Chinese import penetration to South Africa is defined as the average annual change between 2010 and 2016; the average industry-level capability intensities in 2010 are respectively the investment in capital equipment normalized by total sales_INVST $T_{i, 2010}$ - (upper graph) and spending in innovation-related activities (e.g. R\&D and/or royalties)—INNOV ${ }_{i, 2010}$-(bottom graph). Lines are fitted by OLS regression. The 95 per cent confidence interval is based on robust standard errors. In the upper graph, the slope coefficient is -0.006 with robust standard errors 0.002 and $t$-statistic -3.19 . In the bottom graph, the slope coefficient is -0.004 with robust standard errors 0.003 and $t$-statistic -1.32 .

Source: authors' calculations using UN Comtrade (2018) and SARS data. 
In this section, we report the main econometric results of our empirical investigation. First, we present baseline estimates of the impact of Chinese import competition on three measures of firm performance (employment growth, sales growth, firm exit), focusing on the role of investments in capability development activities in mitigating such effects. Second, we expand our baseline analysis to take into account the indirect impact of Chinese import penetration, propagating through intersectoral linkages along the domestic value chain.

\subsection{Employment growth}

We first test the hypothesis that employment growth for surviving firms decreases with Chinese import penetration. ${ }^{37}$ We also explore whether this impact is smaller for firms investing in product and process innovation and skills development.

Results are shown in Table 4 for alternative specifications. All columns report IV (instrumental variable) estimates that use China's import share in other low- and middle-income countries (excluding South Africa) to instrument for the Chinese import penetration variable. Column 1 refers to the baseline specification, including our main variable of interest, $P E N_{s, t}^{c h n}$. In column 2 we add interaction terms of key firm capabilities-related variables (e.g. a battery of dummies taking the value 1 for firms investing in capital equipment, innovation, and training activities) with Chinese import penetration. Finally, in columns 3 and 4 we consider interaction terms of China's import competition with internal (e.g. a dummy indicating investment in R\&D activities) and external product innovation (e.g. a dummy indicating investment in royalties).

As far as firm-level controls are concerned, all variables but firm age and training intensity are significant and exhibit the expected signs. We find that smaller and more capital-investing firms have higher employment growth. Furthermore, employment growth is higher for firms intensively investing in innovation-related activities, although this relation is mainly driven by internal rather than external innovation expenditures (see columns 3 and 4). Interestingly, and in contrast with most of the literature, we find that in the South African manufacturing sector, firm age positively influences employment growth. $^{38}$

\footnotetext{
${ }^{37}$ In some additional unreported estimates (available upon request) we also replicate this exercise on the entire sample, including dying firms, and get very similar results.

${ }^{38}$ Some exceptions have been found to the widely documented evidence that younger firms are more likely to grow faster than older firms. Shanmugam and Bhaduri (2002) for example, show that employment growth is faster for older Indian manufacturing firms. Das (1995), again with reference to India, reports a positive effect of firm age on employment growth in the computer hardware industry.
} 
Table 4: Direct import competition analysis: employment growth: $\Delta \log (E)_{i, t+1}$.

\begin{tabular}{|c|c|c|c|c|}
\hline Dep. variable & $\Delta \log (E)_{i, t+1}$ & & & \\
\hline Specification & (1) & (2) & (3) & (4) \\
\hline Estimation method & IV & IV & IV & IV \\
\hline \multicolumn{5}{|l|}{ Controls } \\
\hline $\log (E)_{i, t}$ & $\begin{array}{c}-0.394^{* * *} \\
(0.006)\end{array}$ & $\begin{array}{c}-0.396^{* * *} \\
(0.006)\end{array}$ & $\begin{array}{c}-0.396^{* * *} \\
(0.006)\end{array}$ & $\begin{array}{c}-0.396 * * * \\
(0.006)\end{array}$ \\
\hline $\log (A g e)_{i, t}$ & $\begin{array}{c}0.074^{* * *} \\
(0.014)\end{array}$ & $\begin{array}{c}0.073^{* * *} \\
(0.014)\end{array}$ & $\begin{array}{c}0.073^{* * *} \\
(0.014)\end{array}$ & $\begin{array}{c}0.073^{* * *} \\
(0.014)\end{array}$ \\
\hline$I N V S T_{i, t}$ & $\begin{array}{c}0.004^{* * *} \\
(0.002)\end{array}$ & $\begin{array}{c}0.004^{* * *} \\
(0.002)\end{array}$ & $\begin{array}{c}0.004^{* * *} \\
(0.002)\end{array}$ & $\begin{array}{c}0.004^{* * *} \\
(0.002)\end{array}$ \\
\hline INNOV $_{i, t}$ & $\begin{array}{c}0.001^{* * *} \\
(0.001)\end{array}$ & $\begin{array}{c}0.001^{* * *} \\
(0.001)\end{array}$ & & \\
\hline$R \& D_{i, t}$ & & & $\begin{array}{c}0.001^{* * *} \\
(0.001)\end{array}$ & \\
\hline$R_{O Y A L_{i, t}}$ & & & & $\begin{array}{c}0.002 \\
(0.004)\end{array}$ \\
\hline $\operatorname{TRAIN}_{i, t}$ & $\begin{array}{l}-0.001 \\
(0.001)\end{array}$ & $\begin{array}{l}-0.001 \\
(0.001)\end{array}$ & $\begin{array}{l}-0.001 \\
(0.001)\end{array}$ & $\begin{array}{l}-0.001 \\
(0.001)\end{array}$ \\
\hline \multicolumn{5}{|c|}{ Import exposure variables } \\
\hline$P E N_{s, t}^{c h n}$ & $\begin{array}{c}-1.333^{* * *} \\
(0.401)\end{array}$ & $\begin{array}{c}-1.489^{* * *} \\
(0.401)\end{array}$ & $\begin{array}{c}-1.499^{* * *} \\
(0.401)\end{array}$ & $\begin{array}{c}-1.482^{\text {*** }} \\
(0.401)\end{array}$ \\
\hline$\times$ (d) $I N V S T_{i, t}$ & & $\begin{array}{c}0.230^{* * *} \\
(0.023)\end{array}$ & $\begin{array}{c}0.231^{* * * *} \\
(0.023)\end{array}$ & $\begin{array}{c}0.231^{* * *} \\
(0.023)\end{array}$ \\
\hline$\times$ (d) $I N N O V_{i, t}$ & & $\begin{array}{l}0.134^{* *} \\
(0.055)\end{array}$ & & \\
\hline$\times$ (d) $R \& D_{i, t}$ & & & $\begin{array}{l}0.150^{* *} \\
(0.075)\end{array}$ & \\
\hline$\times$ (d) $R_{O Y A L_{i, t}}$ & & & & $\begin{array}{l}0.115^{*} \\
(0.068)\end{array}$ \\
\hline$\times$ (d) $T_{R A I N}$ & & $\begin{array}{c}0.149^{* * *} \\
(0.034)\end{array}$ & $\begin{array}{c}0.156^{* * *} \\
(0.035)\end{array}$ & $\begin{array}{c}0.152^{* * *} \\
(0.034)\end{array}$ \\
\hline Constant & $\begin{array}{c}1.058^{* * *} \\
(0.036)\end{array}$ & $\begin{array}{c}1.064^{* * *} \\
(0.036)\end{array}$ & $\begin{array}{c}1.065^{* * *} \\
(0.036)\end{array}$ & $\begin{array}{c}1.065^{* * *} \\
(0.036)\end{array}$ \\
\hline Firm fixed effects & Yes & Yes & Yes & Yes \\
\hline Year dummies & Yes & Yes & Yes & Yes \\
\hline Observations & 90,530 & 90,530 & 90,530 & 90,530 \\
\hline R-squared & 0.3157 & 0.3162 & 0.3161 & 0.3162 \\
\hline Number of firms & 12,959 & 12,959 & 12,959 & 12,959 \\
\hline
\end{tabular}

Notes:

1. Dependent variable is log difference of firm employment between year $t$ and $t+1$.

2. All estimates refer to the subset of surviving firms.

3. All specifications report IV estimates.

4. China's import share in other low- and middle-income countries is used as the instrument for $P E N_{p, s, t}^{c h n}$.

5. Standard errors in parentheses are clustered at both industry and firm level.

${ }^{*} p<0.10,{ }^{* *} p<0.05,{ }^{* * *} p<0.01$

Source: authors' calculations using SARS data. 
Estimation results on the impact of import-exposure variables in all specifications reveal that employment growth is significantly and negatively related to import competition from China. ${ }^{39}$ Taking the coefficient value corresponding to the entire sample of South Africa-based manufacturing firms, in column 1 , we find that a one standard deviation increase in Chinese import penetration (equal to 9.7 percentage points) for the mean firm is associated with a decrease in annual firm employment growth of 12.9 percentage points. However, the implied growth magnitudes of our coefficients are quite small in absolute terms, although being still higher when compared to other similar studies for developed countries (Mion and Zhu 2013). Indeed, considering that the average of Chinese import penetration has steadily increased from 0.0752 to 0.1073 over the $2010-17$ period across the entire sample, our estimates indicate that the rise in import competition from China accounts for a 4.28 per cent loss in manufacturing-wide firm employment growth. ${ }^{40}$

The results on the capital investment, innovation, and training interactions with $P E N_{s, t}^{c h n}$ indicate that firms investing in capabilities are slightly more resilient to such competitive pressure and that Chinese imports are somehow inducing a within-industry reallocation of resources across firms. All the interaction terms in columns 2-4 are significant and positive, revealing that the impact of Chinese import competition on employment growth does depend upon these firms' characteristics. Using the point estimates in column 2, we find that investing in capital equipment, innovation activities, and skills development reduces the negative effect of a one standard deviation increase in Chinese import competition on firm employment growth by $2.2,1.3$, and 1.4 percentage points, respectively. Thus, moving from zero to positive investment in activities related to capability development reduces the effect of import competition only by one-sixth (in the case of capital investments) and one-tenth (in the case of innovation and training expenditures) of the average effect. The direction of these effects is fairly consistent with previous results from advanced countries such as the United States (Hombert and Matray 2018), where the impact on firm performance is significantly smaller in plants investing intensively in R\&D activities. ${ }^{41}$

Table A8 in the Appendix reports estimates including import penetration from other low-wage countries and from the rest of the world (mainly upper-middle- and high-income economies). Results indicate that import competition from China has a similar effect, although of larger magnitude, to import competition from upper-middle- and high-income economies, while we do not find any significant impact of imports from other low-wage countries. This finding confirms the evidence that Chinese exports seem to be more sophisticated and to show more overlap with OECD countries' products with respect to other low-wage countries (Rodrik 2006; Schott et al. 2008).

\subsection{Sales growth}

We employ the same specifications structure used in Table 4 to study whether Chinese import penetration has generated a negative impact on output dynamics of surviving firms. ${ }^{42}$ We also explore whether this impact is smaller for firms investing intensively in product and process innovation and skills development.

\footnotetext{
${ }^{39}$ Table A7 in the Appendix shows side-by-side the OLS and the IV estimates for the main outcome variables analysed in the paper: employment growth, sales growth, and firm exit. As expected, the magnitudes of the $P E N_{s, t}^{c h n}$ coefficients are higher in the IV specifications with respect to OLS ones.

${ }^{40}$ The effect of the increase in Chinese import penetration between 2010 and 2017 is given by the following formula: $-1.333 \times$ $(0.1073-0.0752)=-0.0428$.

${ }^{41}$ In some additional unreported estimates (available upon request) we also include province dummies. The results are not appreciably altered. The same applies to subsequent estimates.

${ }^{42}$ As in the case of employment growth, in some unreported estimates we also replicate this exercise on the entire sample and get very similar results.
} 
As in the case of employment growth, in Table 5 we find that smaller, older, and more capital-investing firms report higher output growth. Furthermore, sales growth is higher for firms intensively investing in R\&D activities, while we do not find any significant relationship between output growth and investments in training and royalties. Estimation results in all specifications reveal that Chinese import competition negatively and significantly affects output growth of surviving firms. Coefficient estimates in column 1 indicate that a one standard deviation increase in Chinese import penetration for the mean firm is associated with a decrease in annual firm employment growth of 13.2 percentage points. The implied growth magnitude of our coefficient shows that the increase in import competition from China between 2010 and 2017 accounts for a 4.39 per cent loss in manufacturing-wide firm sales growth. The results on the capital investment, innovation, and training interactions with $P E N_{s, t}^{c h n}$ indicate that firms investing in capital equipment and innovation activities are slightly more resilient to such competitive pressure. Using the point estimates in column 2, we find that firms investing in capital equipment and innovation activities reduces the negative effect of a one standard deviation increase in Chinese import competition on sales growth by 2.4 and 1.3 percentage points, respectively. Interestingly enough, this latter effect seems to be mainly driven by investments in external product innovation (e.g. royalties), while we do not find any significant impact of $R \& D$ expenditures.

\subsection{Firm exit}

Table 6 displays the relationship between import competition and the probability of firm death. The structure of the different specifications presented is the same as for employment and sales growth.

The results in Table 5 are fairly consistent with previous empirical evidence for size and age. Firm shutdown is negatively associated with firm size, while firm age is positive and significant. This latter finding, in contrast to learning models (Jovanovic 1982) but consistently with previous evidence on Chilean plants (Alvarez and Claro 2009), suggests that older firms are more likely to die. Finally, higher investment intensity in capital reduces the probability of exit in all the specifications, while the impacts of innovation- and training-related investments are never significant.

The coefficient value of Chinese import penetration, corresponding to the entire sample of South Africabased manufacturing firms in column 1 of Table 5, reveals that increasing competitive pressure from China does not significantly affect the likelihood of firm shutdown. However, when considering interactions with firm-level investments in capabilities development, in column $2-4$, it turns out to be significant and positive. Results in column 2 indicate that a one standard deviation increase in Chinese import penetration for the mean firm not investing in any capabilities development activity is associated with a 3.6 percentage points increase in the probability of death. According to our estimates in column 2, the increase in Chinese import penetration between 2010 and 2017 has caused a 1 per cent increase in the shutdown probability for firms not undertaking any investment in capabilities development. The evidence reported in Table 5 is partly in line with results of similar studies, which find a positive and significant impact of import penetration from low-wage countries in general, and in particular from China, both in developed (Autor et al. 2013; Bernard et al. 2006; Bloom et al. 2016), and developing countries (Alvarez and Claro 2009). ${ }^{43}$ The results on the capital investment, innovation, and training interactions with $P E N_{s, t}^{c h n}$ indicate that firms investing in capabilities are more resilient to such competitive pressures and less likely to exit the market. All the interaction terms in columns 2-4 are significant and negative, revealing that investing in capital equipment and innovation activities reduces the negative effect of a one standard deviation increase in Chinese import competition on the probability of firm shutdown by $2.5,0.5$, and 2 percentage points, respectively. Thus, moving from zero to positive investment in cap-

\footnotetext{
${ }^{43}$ Contrary to our results, Mion and Zhu (2013) do not find any significant impact of Chinese import penetration on the probability of exit for Belgian manufacturing firms over the period 1996-2007.
} 
ital equipment reduces the effect of import competition by over two-thirds of the average effect, while spending in innovation and training activities is found to diminish such impact by one-seventh and by over half of the average effect, respectively.

Table 5: Direct import competition analysis: sales growth: $\Delta \log (S)_{i, t+1}$.

\begin{tabular}{|c|c|c|c|c|}
\hline Dep. variable & $\Delta \log (S)_{i, t+1}$ & & & \\
\hline Specification & (1) & (2) & (3) & (4) \\
\hline Estimation method & IV & IV & IV & IV \\
\hline \multicolumn{5}{|l|}{ Controls } \\
\hline $\log (E)_{i, t}$ & $\begin{array}{c}-0.365^{* * *} \\
(0.010)\end{array}$ & $\begin{array}{c}-0.364^{* * *} \\
(0.010)\end{array}$ & $\begin{array}{c}-0.364^{* * *} \\
(0.010)\end{array}$ & $\begin{array}{c}-0.364^{* * *} \\
(0.010)\end{array}$ \\
\hline $\log (A g e)_{i, t}$ & $\begin{array}{c}0.058^{* * *} \\
(0.014)\end{array}$ & $\begin{array}{c}0.059^{* * *} \\
(0.014)\end{array}$ & $\begin{array}{c}0.059^{* * *} \\
(0.014)\end{array}$ & $\begin{array}{c}0.059^{* * *} \\
(0.014)\end{array}$ \\
\hline$I_{N V S T}$ & $\begin{array}{c}0.001^{* * *} \\
(0.001)\end{array}$ & $\begin{array}{c}0.001^{* * *} \\
(0.001)\end{array}$ & $\begin{array}{c}0.001^{* * *} \\
(0.001)\end{array}$ & $\begin{array}{c}0.001^{* * *} \\
(0.001)\end{array}$ \\
\hline INNOV $_{i, t}$ & $\begin{array}{c}0.003 \\
(0.002)\end{array}$ & $\begin{array}{c}0.003 \\
(0.002)\end{array}$ & & \\
\hline$R \& D_{i, t}$ & & & $\begin{array}{l}0.001^{* *} \\
(0.001)\end{array}$ & \\
\hline$R O Y A L_{i, t}$ & & & & $\begin{array}{c}0.005 \\
(0.004)\end{array}$ \\
\hline $\operatorname{TRAIN}_{i, t}$ & $\begin{array}{l}-0.001 \\
(0.001)\end{array}$ & $\begin{array}{l}-0.001 \\
(0.001)\end{array}$ & $\begin{array}{l}-0.001 \\
(0.001)\end{array}$ & $\begin{array}{l}-0.001 \\
(0.001)\end{array}$ \\
\hline \multicolumn{5}{|c|}{ Import exposure variables } \\
\hline$P E N_{s, t}^{c h n}$ & $\begin{array}{c}-1.367^{* * *} \\
(0.415)\end{array}$ & $\begin{array}{c}-1.404^{* * *} \\
(0.415)\end{array}$ & $\begin{array}{c}-1.404^{* * *} \\
(0.415)\end{array}$ & $\begin{array}{c}-1.399^{* * *} \\
(0.415)\end{array}$ \\
\hline$\times(\mathrm{d}) I N V S T_{i, t}$ & & $\begin{array}{c}0.232^{* * *} \\
(0.022)\end{array}$ & $\begin{array}{c}0.233^{* * *} \\
(0.022)\end{array}$ & $\begin{array}{c}0.233^{* * *} \\
(0.022)\end{array}$ \\
\hline$\times$ (d) $I_{N N O V_{i, t}}$ & & $\begin{array}{l}0.122^{* *} \\
(0.059)\end{array}$ & & \\
\hline$\times$ (d) $R \& D_{i, t}$ & & & $\begin{array}{c}0.065 \\
(0.089)\end{array}$ & \\
\hline$\times$ (d) $R O Y A L_{i, t}$ & & & & $\begin{array}{l}0.143^{*} \\
(0.075)\end{array}$ \\
\hline$\times$ (d) $T_{R A}{ }^{\prime} N_{i, t}$ & & $\begin{array}{c}0.055 \\
(0.038)\end{array}$ & $\begin{array}{c}0.042 \\
(0.037)\end{array}$ & $\begin{array}{c}0.038 \\
(0.037)\end{array}$ \\
\hline Constant & $\begin{array}{c}5.860^{* * *} \\
(0.158)\end{array}$ & $\begin{array}{c}5.879^{* * *} \\
(0.160)\end{array}$ & $\begin{array}{c}5.858^{* * *} \\
(0.159)\end{array}$ & $\begin{array}{c}5.855^{* * *} \\
(0.159)\end{array}$ \\
\hline Firm fixed effects & Yes & Yes & Yes & Yes \\
\hline Year dummies & Yes & Yes & Yes & Yes \\
\hline Observations & 86,289 & 86,289 & 86,289 & 86,289 \\
\hline R-squared & 0.2196 & 0.2198 & 0.2195 & 0.2196 \\
\hline Number of firms & 12,919 & 12,919 & 12,919 & 12,919 \\
\hline
\end{tabular}

Notes:

1. Dependent variable is log difference of firm sales between year $t$ and $t+1$.

2. All estimates refer to the subset of surviving firms.

3. All specifications report IV estimates.

4. China's import share in other low- and middle-income countries is used as the instrument for $P E N_{s, t}^{c h n}$.

5. Standard errors in parentheses are clustered at both industry and firm level.

${ }^{*} p<0.10,{ }^{* *} p<0.05,{ }^{* * *} p<0.01$.

Source: authors' calculations using SARS data. 
Table 6: Direct import competition analysis: firm exit: Death $_{i, t+1}$.

\begin{tabular}{|c|c|c|c|c|}
\hline Dep. variable & Death $_{i, t+1}$ & & & \\
\hline Specification & (1) & (2) & (3) & (4) \\
\hline Estimation method & IV & IV & IV & IV \\
\hline \multicolumn{5}{|l|}{ Controls } \\
\hline $\log (E)_{i, t}$ & $\begin{array}{c}-0.056^{* * *} \\
(0.002)\end{array}$ & $\begin{array}{c}-0.052^{* * *} \\
(0.002)\end{array}$ & $\begin{array}{c}-0.052^{* * *} \\
(0.002)\end{array}$ & $\begin{array}{c}-0.052^{* * *} \\
(0.002)\end{array}$ \\
\hline $\log (A g e)_{i, t}$ & $\begin{array}{c}0.127^{* * *} \\
(0.006)\end{array}$ & $\begin{array}{c}0.133^{* * *} \\
(0.006)\end{array}$ & $\begin{array}{c}0.133^{* * *} \\
(0.006)\end{array}$ & $\begin{array}{c}0.133^{* * *} \\
(0.006)\end{array}$ \\
\hline$I N V S T_{i, t}$ & $\begin{array}{c}-0.002^{* * *} \\
(0.001)\end{array}$ & $\begin{array}{c}-0.002^{* * *} \\
(0.001)\end{array}$ & $\begin{array}{c}-0.002^{* * *} \\
(0.001)\end{array}$ & $\begin{array}{c}-0.002^{* * *} \\
(0.001)\end{array}$ \\
\hline INNOV $_{i, t}$ & $\begin{array}{l}-0.001 \\
(0.001)\end{array}$ & $\begin{array}{l}-0.001 \\
(0.001)\end{array}$ & & \\
\hline$R \& D_{i, t}$ & & & $\begin{array}{l}-0.001 \\
(0.001)\end{array}$ & \\
\hline $\operatorname{ROYAL}_{i, t}$ & & & & $\begin{array}{l}-0.001 \\
(0.004)\end{array}$ \\
\hline $\operatorname{TRAIN}_{i, t}$ & $\begin{array}{l}-0.001 \\
(0.001)\end{array}$ & $\begin{array}{l}-0.001 \\
(0.001)\end{array}$ & $\begin{array}{l}-0.001 \\
(0.001)\end{array}$ & $\begin{array}{l}-0.001 \\
(0.001)\end{array}$ \\
\hline \multicolumn{5}{|c|}{ Import exposure variables } \\
\hline$P E N_{s, t}^{c h n}$ & $\begin{array}{c}0.204 \\
(0.180)\end{array}$ & $\begin{array}{c}0.370^{* *} \\
(0.180)\end{array}$ & $\begin{array}{c}0.372^{* *} \\
(0.162)\end{array}$ & $\begin{array}{l}0.368^{* *} \\
(0.180)\end{array}$ \\
\hline$\times(\mathrm{d}) I N V S T_{i, t}$ & & $\begin{array}{c}-0.255^{* * *} \\
(0.012)\end{array}$ & $\begin{array}{c}-0.255^{* * *} \\
(0.012)\end{array}$ & $\begin{array}{c}-0.255^{* * *} \\
(0.012)\end{array}$ \\
\hline$\times$ (d) $I N N O V_{i, t}$ & & $\begin{array}{c}-0.037^{*} \\
(0.020)\end{array}$ & & \\
\hline$\times(\mathrm{d}) R \& D_{i, t}$ & & & $\begin{array}{l}-0.022 \\
(0.031)\end{array}$ & \\
\hline$\times$ (d) $R O Y A L_{i, t}$ & & & & $\begin{array}{l}-0.039 \\
(0.068)\end{array}$ \\
\hline$\times(\mathrm{d}) T R A I N_{i, t}$ & & $\begin{array}{c}-0.204^{* * *} \\
(0.015)\end{array}$ & $\begin{array}{c}-0.206^{* * *} \\
(0.015)\end{array}$ & $\begin{array}{c}-0.204^{* * *} \\
(0.015)\end{array}$ \\
\hline Constant & $\begin{array}{c}-0.176^{* * *} \\
(0.020)\end{array}$ & $\begin{array}{c}-0.196^{* * *} \\
(0.020)\end{array}$ & $\begin{array}{c}-0.197^{* * *} \\
(0.020)\end{array}$ & $\begin{array}{c}-0.196^{* * *} \\
(0.020)\end{array}$ \\
\hline Firm fixed effects & Yes & Yes & Yes & Yes \\
\hline Year dummies & Yes & Yes & Yes & Yes \\
\hline Observations & 134,395 & 134,395 & 134,395 & 134,395 \\
\hline R-squared & 0.0735 & 0.0753 & 0.0753 & 0.0753 \\
\hline Number of firms & 23,170 & 23,170 & 23,170 & 23,170 \\
\hline
\end{tabular}

Notes:

1. Dependent variable is a dummy indicating firm death in year $t+1$.

2. A linear probability model is used in all specifications.

3. All specifications report IV estimates.

4. China's import share in other low- and middle-income countries is used as the instrument for $P E N_{s, t}^{c h n}$.

5. Standard errors in parentheses are clustered at both industry and firm level.

${ }^{*} p<0.10,{ }^{* *} p<0.05,{ }^{* * *} p<0.01$.

Source: authors' calculations using SARS data. 


\subsection{Accounting for sectoral linkages}

Tables 7 and 8 report IV estimates of the impacts of Chinese import exposure on employment and sales growth and the probability of shutdown for South Africa-based firms, analogous to those in Tables 4, 5 , and 6, here including also the indirect import exposure measures. Specifically, panel A refers to the effects of the first-order indirect import exposure measures, and panel B employs the full Leontief variants. All specifications include the constant and all the firm-level controls used in the previous estimates in Tables 4-6 (unreported, to facilitate readability).

Columns 1-3 of Table 7 report the results of the impact of direct and indirect Chinese import penetration on employment decisions of firms. On the one hand, downstream import effects represented in Figure 2 are negative in sign but never statistically significant (see columns 2 and 3), consistent with Acemoglu et al. (2016) and Hombert and Matray (2018). This might be explained by the fact that in the case of South Africa the increased availability of cheaper foreign imports is offset by a reduction of domestic input supply (e.g. South African-based suppliers might reduce shipments in light of higher import competition). On the other hand, the upstream import effect described in Figure 2 is quite stable across specifications and, in line with our expectations, it has a negative and significant impact on firm employment growth. Coefficient estimates in column 1 indicate that a one standard deviation increase in upstream Chinese import penetration (equal to 2.6 percentage points) for the mean firm is associated with a decrease in annual firm employment growth of 7.5 percentage points. Given the non-significance of the impact arising through downstream sectoral interdependencies, in columns 4 and 5 we focus on the upstream effects, regressing firm employment growth on a combined direct-upstream exposure measure, consisting of their sum. As expected, the estimated coefficient on this combined effect lies between the coefficients on the direct and upstream impacts estimated in column 1. Furthermore, the results in column 5 indicate that firms investing in capabilities development are also more resilient to Chinese import competition pressure affecting their buyers in downstream segments of the value chain. Indeed, investing in capital equipment, innovation, and training activities reduces the negative effect of a one standard deviation increase in the combined direct-upstream Chinese import penetration on employment growth by $2.1,1.3$, and 1.2 percentage points, respectively. Panel B of Table 7 reveals a very similar pattern in terms of results. Overall, in this case, the coefficients on the full exposure measures are slightly smaller in magnitude (but also more precisely estimated) than those reported in panel A on the first-order indirect import exposure.

Table 8 reports the results of the impact of direct and indirect Chinese import penetration on output dynamics and probability of shutdown of South Africa-based manufacturing firms. As for the case of employment growth, we decide to focus on the upstream effects, regressing firm sales growth and the probability of shutdown on the sum of direct and upstream exposure measures as in columns 4 and 5 of Table $7{ }^{44}$ The results in columns 2 and 4 confirm that firms investing in capabilities development are more resilient even to competitive pressure in downstream segments of the value chain. As in Table 5, we do not find any significant impact of training expenditures on firm sales growth.

\footnotetext{
${ }^{44}$ Unreported estimates (available upon request) show that the effects propagating through downstream sectoral linkages are not statistically significant also in the case of sales growth and probability of exiting the market.
} 
Table 7: Indirect import competition analysis: employment growth: $\Delta \log (E)_{i, t+1}$.

\begin{tabular}{|c|c|c|c|c|c|}
\hline Dep. variable & $\Delta \log (E)_{i, t+1}$ & & & & \\
\hline Specification & (1) & (2) & (3) & (4) & (5) \\
\hline Estimation method & IV & IV & IV & IV & IV \\
\hline \multicolumn{6}{|c|}{ A. First-order indirect import exposure variables } \\
\hline$P E N_{s, t}^{c h n}$ & $\begin{array}{c}-1.235^{* * *} \\
(0.369)\end{array}$ & $\begin{array}{c}-1.325^{* * *} \\
(0.412)\end{array}$ & $\begin{array}{c}-1.237^{* * *} \\
(0.371)\end{array}$ & & \\
\hline$P E N_{s, t}^{c h n, u p}$ & $\begin{array}{c}-2.885^{* * *} \\
(0.843)\end{array}$ & & $\begin{array}{c}-3.013^{* * *} \\
(0.840)\end{array}$ & & \\
\hline$P E N_{s, t}^{c h n, d o w n}$ & & $\begin{array}{l}-0.091 \\
(0.759)\end{array}$ & $\begin{array}{l}-0.652 \\
(0.746)\end{array}$ & & \\
\hline$P E N_{s, t}^{c h n}+P E N_{s, t}^{c h n, u p}$ & & & & $\begin{array}{c}-1.245^{* * *} \\
(0.373)\end{array}$ & $\begin{array}{c}-1.369^{* * *} \\
(0.358)\end{array}$ \\
\hline$\times(\mathrm{d}) I N V S T_{i, t}$ & & & & & $\begin{array}{c}0.208^{* * * *} \\
(0.020)\end{array}$ \\
\hline$\times(\mathrm{d}) \mathrm{INNOV}_{i, t}$ & & & & & $\begin{array}{c}0.127^{* * *} \\
(0.048)\end{array}$ \\
\hline$\times$ (d) $\operatorname{TRAIN}_{i, t}$ & & & & & $\begin{array}{c}0.123^{* * *} \\
(0.030)\end{array}$ \\
\hline
\end{tabular}

B. Full (higher-order) indirect import exposure variables

\begin{tabular}{|c|c|c|c|c|c|}
\hline$P E N_{s, t}^{c h n}$ & $\begin{array}{c}-1.304^{* * *} \\
(0.368)\end{array}$ & $\begin{array}{c}-1.340^{* * *} \\
(0.414)\end{array}$ & $\begin{array}{c}-1.311^{* * *} \\
(0.371)\end{array}$ & & \\
\hline$P E N_{s, t}^{c h n, u p}$ & $\begin{array}{c}-2.487^{* * *} \\
(0.695)\end{array}$ & & $\begin{array}{c}-2.582^{* * *} \\
(0.697)\end{array}$ & & \\
\hline$P E N_{s, t}^{\text {chn,down }}$ & & $\begin{array}{l}-0.074 \\
(0.656)\end{array}$ & $\begin{array}{l}-0.622 \\
(0.640)\end{array}$ & & \\
\hline$P E N_{s, t}^{c h n}+P E N_{s, t}^{c h n, u p}$ & & & & $\begin{array}{c}-1.322^{* * *} \\
(0.373)\end{array}$ & $\begin{array}{c}-1.440^{* * *} \\
(0.373)\end{array}$ \\
\hline$\times$ (d) $I N V S T_{i, t}$ & & & & & $\begin{array}{c}0.202^{* * *} \\
(0.019)\end{array}$ \\
\hline$\times$ (d) $I N N O V_{i, t}$ & & & & & $\begin{array}{c}0.128^{* * *} \\
(0.046)\end{array}$ \\
\hline$\times$ (d) $T_{R A}{ }^{\prime} N_{i, t}$ & & & & & $\begin{array}{c}0.117^{* * *} \\
(0.028)\end{array}$ \\
\hline Firm fixed effects & Yes & Yes & Yes & Yes & Yes \\
\hline Year dummies & Yes & Yes & Yes & Yes & Yes \\
\hline Observations & 90,530 & 90,530 & 90,530 & 90,530 & 90,530 \\
\hline Number of firms & 12,959 & 12,959 & 12,959 & 12,959 & 12,959 \\
\hline
\end{tabular}

Notes:

1. Dependent variables are log difference of firm employment between year $t$ and $t+1$.

2. All estimates refer to the subset of surviving firms.

3. All specifications include the constant and all controls used in previous estimates.

4. All specifications report IV estimates.

5. China's import share in other low- and middle-income countries is used as the instrument for $P E N_{s, t}^{c h n}$.

6. Standard errors in parentheses are clustered at both industry and firm level.

${ }^{*} p<0.10,{ }^{* *} p<0.05,{ }^{* * *} p<0.01$.

Source: authors' calculations using SARS data. 
Table 8: Indirect import competition analysis: sales growth, firm death: $\Delta \log (S)_{i, t+1}$, Death $h_{i, t+1}$

\begin{tabular}{|c|c|c|c|c|}
\hline Dep. variable & $\Delta \log (S)_{i, t+1}$ & $\Delta \log (S)_{i, t+1}$ & Death $_{i, t+1}$ & Death $_{i, t+1}$ \\
\hline Specification & (1) & (2) & (3) & (4) \\
\hline Estimation method & IV & IV & IV & IV \\
\hline \multicolumn{5}{|c|}{ A. First-order indirect import exposure variables } \\
\hline$P E N_{s, t}^{c h n}+P E N_{s, t}^{c h n, u p}$ & $\begin{array}{c}-1.053^{* * *} \\
(0.368)\end{array}$ & $\begin{array}{c}-1.079^{* * *} \\
(0.369)\end{array}$ & $\begin{array}{c}0.174 \\
(0.160)\end{array}$ & $\begin{array}{c}0.307^{* *} \\
(0.153)\end{array}$ \\
\hline$\times(\mathrm{d}) I N V S T_{i, t}$ & & $\begin{array}{l}0.045^{* *} \\
(0.022)\end{array}$ & & $\begin{array}{c}-0.222^{* * *} \\
(0.010)\end{array}$ \\
\hline$\times$ (d) $I_{N N O V}$ & & $\begin{array}{l}0.108^{* *} \\
(0.051)\end{array}$ & & $\begin{array}{c}-0.032^{* *} \\
(0.017)\end{array}$ \\
\hline$\times(\mathrm{d}) T R A I N_{i, t}$ & & $\begin{array}{c}0.042 \\
(0.032)\end{array}$ & & $\begin{array}{c}-0.176^{* * *} \\
(0.013)\end{array}$ \\
\hline \multicolumn{5}{|c|}{ B. Full (higher-order) indirect import exposure variables } \\
\hline$P E N_{s, t}^{c h n}+P E N_{s, t}^{c h n, u p}$ & $\begin{array}{c}-1.023^{* * *} \\
(0.383)\end{array}$ & $\begin{array}{c}-1.047^{* * *} \\
(0.383)\end{array}$ & $\begin{array}{c}0.169 \\
(0.165)\end{array}$ & $\begin{array}{c}0.296^{* *} \\
(0.163)\end{array}$ \\
\hline$\times(\mathrm{d}) I N V S T_{i, t}$ & & $\begin{array}{l}0.044^{* *} \\
(0.021)\end{array}$ & & $\begin{array}{c}-0.214^{* * *} \\
(0.010)\end{array}$ \\
\hline$\times(\mathrm{d}) \mathrm{INNOV}_{i, t}$ & & $\begin{array}{l}0.105^{* *} \\
(0.049)\end{array}$ & & $\begin{array}{c}-0.031^{* *} \\
(0.017)\end{array}$ \\
\hline$\times(\mathrm{d}) T R A I N_{i, t}$ & & $\begin{array}{c}0.040 \\
(0.031)\end{array}$ & & $\begin{array}{c}-0.169^{* * *} \\
(0.012)\end{array}$ \\
\hline Firm fixed effects & Yes & Yes & Yes & Yes \\
\hline Year dummies & Yes & Yes & Yes & Yes \\
\hline Observations & 86,289 & 86,289 & 134,395 & 134,395 \\
\hline Number of firms & 12,919 & 12,919 & 12,959 & 12,959 \\
\hline
\end{tabular}

Notes:

1. Dependent variable in (1) and (2) is log difference of firm sales between year $t$ and $t+1$.

2. Dependent variable in (3) and (4) is a dummy indicating firm death in year $t+1$.

3. A linear probability model is used in (3) and (4).

4. Estimates in (1) and (2) refer to the subset of surviving firms.

5. All specifications include the constant and all controls used in previous estimates.

6. All specifications report IV estimates.

7. China's import share in other low- and middle-income countries is used as the instrument for $P E N_{s, t}^{c h n}$.

8. Standard errors in parentheses are clustered at both industry and firm level.

${ }^{*} p<0.10,{ }^{* *} p<0.05,{ }^{* * *} p<0.01$.

Source: authors' calculations using SARS data. 
In this paper we employ a unique firm-level database made available by SARS to analyse the impact of Chinese import competition in manufacturing industries on the performances of the South Africa-based manufacturing firms from 2010 to 2017. Due to possible endogeneity and reverse causality issues, we instrument Chinese import penetration using China's share in other low- and middle-income countries' imports following an identification strategy inspired by Autor et al. (2013). Thus, we study two categories of margins of adjustments in manufacturing firms in South Africa. First, we explore whether China's import exposure-both direct (e.g. affecting the sector where the firm itself operates) and indirect (e.g. through input-output linkages along the domestic value chain)—have been associated with a downsizing of manufacturing firms in terms of decreasing employment and sales growth and higher probability of exiting the market. Second, we examine whether firms investing in process and product innovation and skills development are better able to cope with import competition.

Our results indicate that rising direct Chinese import exposure has negatively affected employment and sales growth of surviving firms, and increased the probability of shutdown for the subset of companies not investing in capabilities development. The implied growth magnitude of such effects is rather limited, but still relatively high when compared to other similar studies for advanced economies (Mion and Zhu 2013). According to our estimates, indeed, the increase in direct Chinese import penetration between 2010 and 2017 accounts for around 4.28 per cent and 4.39 per cent of the loss in manufacturingwide firm employment growth and sales growth in South Africa, respectively, and has caused a 1 per cent increase in the shutdown probability for firms not investing in capital equipment, innovation, and training programmes. In line with our expectations (see Figure 2), upstream import effects—originating in downstream segments of the domestic value chain (i.e. propagating upstream) — contribute to reduced firm employment, sales growth, and survival rates. Thus, an increase in Chinese import penetration in a given industry has a negative impact on the performance of firms supplying intermediate inputs to the affected sector. Conversely, downstream import effects are never statistically significant. This might be explained by the fact that in the South African case the positive effect of increased availability of cheaper foreign imports is offset by the disruption of existing long-term supply relations for specialized domestic inputs (e.g. South Africa-based suppliers might reduce shipments in light of higher import competition). Thus, at least on average we cannot detect significant effects of firms responding to the supply of cheaper foreign inputs by expanding employment and production.

As far as heterogeneity is concerned, we find that these negative effects are only slightly smaller for firms investing in process and product innovation and in skills development programmes. In almost all estimates the interaction term between the Chinese import competition variable and our capabilitiesrelated binary proxies has a significant and positive impact, revealing that firms investing in capabilities development are more resilient to such competitive pressures. However, such effects are extremely weak and unable to counterbalance the negative impact of Chinese import penetration. Building on these results, in what follows we highlight some policy implications.

Since the end of apartheid, the South African government has struggled to promote structural transformation, employment creation, and domestic value-addition in manufacturing. Several policy measures have attempted to address South African premature deindustrialization, with mixed results across sectors and firms (e.g. several rounds of the Industrial Policy Action Plan (IPAP)). Our empirical evidence has pointed to a relatively new but increasingly important policy challenge, that is the impact of Chinese import penetration on the expansionary dynamics of South African manufacturing firms.

The increase in direct Chinese import penetration between 2010 and 2017 has been estimated to account for around 4 per cent of the loss in manufacturing-wide firm employment growth and sales growth in 
South Africa, alongside a crowding-out process propagating upstream along the domestic value chain from the firms directly affected by Chinese imports to their suppliers (i.e. indirect upstream impact). This double negative impact is critical as it results in the increasing disarticulation of the local production system and weakening of its nodes, while introducing further challenges in the implementation of localization policies aiming at increasing domestic value-addition and linkages development. Understanding the competitiveness gap in terms of capabilities, price, and quality-in specific sectors and for specific product segments-between Chinese imported goods and South African firms becomes a key policy priority towards feasible interventions. In this respect, our econometric results suggest how firms investing in capabilities development have managed to respond to Chinese import penetration in a relatively more effective way. ${ }^{45}$

While this latter result is encouraging and highlights the importance of supporting investment in production upgrading (including functional repositioning along the value chain), research, and skills, the fact that the negative impact of Chinese import penetration is still significant and only marginally smaller for firms investing in capabilities development points to further policy considerations. First, capabilities development and accumulation take time, and scale-appropriate and sustained investment efforts. The fact that only a very small percentage of firms are involved in significant investments, and that even within this group a number of firms show limited and discontinuous investment commitment, is alarming. Second, the fact that in South Africa a limited number of firms are investing also means that firms cannot benefit from the externality typical of an industrial ecosystem with multiple firms specializing in complementary capabilities and involved in lateral migration (Andreoni 2019). Finally, given their small scale, domestic orientation, and limited access to industrial finance, if suppliers along the chain are crowded-out by Chinese imports, it also means they cannot immediately benefit from their investments in capabilities while their market and buyers shrink.

Chinese import penetration and competitive pressure are thus intertwined with a number of long-term structural problems of the South African production system as a whole, and specific weaknesses of its firms along several domestic value chains, including higher-value ones. Indeed, the increasing impact of Chinese imports towards higher-value and more technologically intensive sectors like machinery finally points to the need for better understanding of the changing nature of import competition and the importance of coordinated intervention in those sectors where South Africa retains a competitive edge.

\footnotetext{
${ }^{45}$ However, because of data limitations, this study could not open the black box of the mechanisms through which firms investing in capabilities development can mitigate the impact of increasing Chinese import penetration. Further firm-level and sectoral value chain-level investigations are required to unpack the structural mechanisms and specific competitive pressures South Africa-based firms are exposed to and their reactions to these.
} 


\section{References}

Acemoglu, D., V.M. Carvalho, and A. Ozdaglar (2012). 'The network origins of aggregate fluctuations'. Econometrica, 80 (5): 1977-2016.

Acemoglu, D., D.H. Autor, D. Dorn, G.H. Hanson, and B. Price (2016). 'Import Competition and the Great U.S. Employment Sag of the 2000s'. Journal of Labor Economics, 34(S1): S142-98.

Alvarez, R., and S. Claro (2009). 'David Versus Goliath: The Impact of Chinese Competition on Developing Countries'. World Development, 37(3): 560-71.

Andreoni, A. (2014). 'Structural Learning: Embedding Discoveries and the Dynamics of Production'. Structural Change and Economic Dynamics, 29: 58-74.

Andreoni, A. (2019). 'A Generalised Linkage Approach to Local Production Systems Development in the Era of Global Value Chains, with Special Reference to Africa'. In A. Noman, R. Kanbur, and J. Stiglitz (eds), Quality of Growth in Africa. New York: Columbia University Press.

Andreoni, A., and H. Chang (2019). 'The Political Economy of Industrial Policy: Structural Interdependencies, Policy Alignment and Conflict Management'. Structural Change and Economic Dynamics, 48(C): 136-50.

Andreoni, A., and F. Tregenna (2018). 'Stuck in the Middle: Premature De-industrialisation and Industrial Policy’. IDTT Working Paper. Johannesburg: IDTT.

Autor, D.H., D. Dorn, and G.H. Hanson (2013). 'The China Syndrome: Local Labor Market Effects of Import Competition in the United States'. American Economic Review, 103(6): 2121-68.

Baldwin, R., and F. Robert-Nicoud (2014). 'Trade-in-Goods and Trade-in-Tasks: An Integrating Framework'. Journal of International Economics, 92(1): 51-62.

Balsvik, R., S. Jensen, and K.G. Salvanes (2015). 'Made in China, Sold in Norway: Local Labor Market Effects of an Import Shock'. Journal of Public Economics, 127(7): 137-44.

Bell, M., and K. Pavitt (1993). 'Technological Accumulation and Industrial Growth: Contrast between Developed and Developing Countries'. Technology, Globalisation and Economic Performance, 2(2): 157-210.

Bernard, A.B., and J.B. Jensen (2004). 'Why Some Firms Export'. The Review of Economics and Statistics, 86 (2): 447-64.

Bernard, A.B., J.B. Jensen, and P.K. Schoot (2006). 'Survival of the Best Fit: Exposure to Low-Wage Countries and the (Uneven) Growth of U.S. Manufacturing Plants'. Journal of International Economics, 68 (1): 219-37.

Bloom, N., M. Draca, and J. Van Reenen (2016). 'Trade Induced Technical Change? The Impact of Chinese Imports on Innovation, IT and Productivity'. Review of Economic Studies, 83 (1): 87-117.

Branstetter, L., and N. Lardy (2006). 'China's Embrace of Globalization'. NBER Working Paper. Cambridge, MA: NBER.

Cameron, A.C., J.B. Gelbach, and D.L. Miller (2011). 'Robust Inference with Multi-Way Clustering'. Journal of Business and Economic Statistics, 29(2): 238-49.

Cherif, R., and F. Hasanov (2019). 'The Return of the Policy that Shall Not be Named: Principles of Industrial Policy'. IMF Working Paper 19/74. Washington, DC: IMF. 
Cohen, W.M., and D.A. Levinthal (1989). 'Innovation and Learning: The Two Faces of R\&D'. The Economic Journal, 99 (397): 569-96.

Contreras, M., and G. Fagiolo (2014). 'Propagation of Economic Shocks in Input-Output Networks: A Cross-Country Analysis'. Physical Review E, 90(6): 062812.

Das, S. (1995). 'Size, Age and Firm Growth in an Infant Industry: The Computer Hardware Industry in India'. International Journal of Industrial Organization, 13(1): 111-26.

Donoso, V., V. Martin, and A. Minondo (2015). 'Do Differences in the Exposure to Chinese Impacts Lead to Differences in Local Labour Market Outcomes? An Analysis for Spanish Provinces'. Regional Studies, 49(10): 1746-64.

Dosi, G., K. Pavitt, and L. Soete (1990). The Economics of Technical Change and International Trade. London: New York University Press.

Dosi, G., R.R. Nelson, and S. Winter (2000). The Nature and Dynamics of Organizational Capabilities. Oxford: Oxford University Press.

Edwards, L., and R. Jenkins (2014). 'The Margins of Export Competition: A New Approach to Evaluating the Impact of China on South African Exports to Sub-Saharan Africa'. Journal of Policy Modeling, 36(1): S132-50.

Edwards, L., and R. Jenkins (2015). 'The Impact of Chinese Import Penetration on the South African Manufacturing Sector'. The Journal of Development Studies, 51(4): 447-63.

Erten, B., J. Leight, and F. Tregenna (2019). 'Trade Liberalization and Local Labor Adjustment in South Africa?'. Journal of International Economics, 118(5): 448-67.

Fedderke, J. (2006). 'Technology, Human Capital and Growth: Evidence from a Middle Income Country Case Study Applying Dynamic Heterogeneous Panel Analysis'. In South African Reserve Bank, Banco de Mexico and The People's Bank of China (eds), Economic Growth, proceedings of a G20 seminar held in Pretoria, South Africa, 4-5 August 2005. Pretoria: South African Reserve Bank.

Fu, X. (2016). China's Path to Innovation. Cambridge: Cambridge University Press.

Goldberg, P.K., A.K. Khandelwal, N. Pavcnik, and P. Topalova (2010). 'Imported Intermediate Inputs and Domestic Product Growth: Evidence from India'. The Quarterly Journal of Economics, 125(4): 1727-67.

Haraguchi, N., C. Fang, and E. Smeets (2017). 'The Importance of Manufacturing in Economic Development: Has this Changed?'. World Development, 93(C): 293-315.

Hatzichronoglou, T. (1997). 'Revision of the High-Technology Sector and Product Classification'. OECD Science, Technology and Industry Working Paper. Paris: OECD.

Hirschman, A.O. (1958). The Strategy of Economic Development. New Haven CT: Yale University Press.

Hirschman, A.O. (1997). 'A Generalised Linkage Approach to Development, with Special Reference to Staples'. Economic Development and Cultural Change, 25: 67-98.

Hombert, J., and A. Matray (2018). 'Can Innovation Help U.S. Manufacturing Firms Escape Import Competition from China?'. The Journal of Finance, 73(5): 2003-2039.

Iacovone, L., F. Rauch, and L.A. Winters (2013). 'Trade as an Engine of Creative Destruction: Mexican Experience with Chinese Competition'. Journal of International Economics, 89(2): 379-92. 
Javorcik, B.S. (2004). 'Does Foreign Direct Investment Increase the Productivity of Domestic Firms? In Search of Spillovers through Backward Linkages'. American Economic Review, 94(3): 605-27.

Javorcik, B.S., and M. Spatareanu (2011). 'Does it Matter Where You Come From? Vertical Spillovers from Foreign Direct Investment and the Origin of Investors'. Journal of Development Economics, 96(1): 126-38.

Jenkins, R. (2008). 'Trade, Technology and Employment in South Africa'. The Journal of Development Studies, 44(1): 60-79.

Jovanovic, B. (1982). 'Selection and Evolution of Industries'. Econometrica, 50(3): 649-70.

Kaplinsky, R. (2008). 'What Does the Rise of China do for Industrialisation in Sub-Saharan Africa?'. Review of African Political Economy, 35(115): 7-22.

Kreuser, C.F., and C. Newman (2018). 'Total Factor Productivity in South African Manufacturing Firms'. South African Journal of Economics, 86(S1): 40-78.

Krugman, P. (1980). 'Scale Economies, Product Differentiation, and the Pattern of Trade'. American Economic Review, 70(5): 950-59.

Lall, S. (1992). ‘Technological Capabilities and Industrialization'. World Development, 20(2): 165-86.

Lall, S. (1999). The Technological Response to Import Liberalization in Sub-Saharan Africa. London: United Nations University and Macmillan.

Lall, S. (2000). 'The Technological Structure and Performance of Developing Country Manufactured Exports, 1985-98'. Oxford Development Studies, 28(3): 337-69.

Lall, S., and M. Alaladejo (2004). 'China's Competitive Performance: A Threat to East Asian Manufactured Exports?'. World Development, 32(9): 1441-66.

Lall, S., and J. Weiss (2005). 'China's Competitive Threat to Latin America: An Analysis for 1990-2002'. Oxford Development Studies, 33(2): 163-94.

Lee, K. (2013). Schumpeterian Analysis of Economic Catch-up: Knowledge, Path-Creation, and the Middle-Income Trap. Cambridge: Cambridge University Press.

Lee, K., Z. Mao, and M. Szapiro (2018). 'From Global Value Chains (GVC) to Innovation Systems for Local Value Chains and Knowledge Creation'. European Journal of Development Research, 30 (3): $424-41$.

Lin, J., and H.J. Chang (2009). 'Should Industrial Policy in Developing Countries Conform to Comparative Advantage or Defy It? A Debate Between Justin Lin and Ha-Joon Chang'. Development Policy Review, 27(5): 483-502.

Lin, J.Y. (2011). 'China and the Global Economy'. China Economic Journal, 4(1): 1-14.

Mail \& Guardian (2012). 'South Africa and China in Awkward Embrace'. Available at: http://mg • co . za/article/2012-07-19-south-africa-and-china-in-awkward-embrace, accessed 1 August 2019.

Malgouyers, C. (2016). 'The Impact of Chinese Import Competition on Employment and the Wage Distribution: Evidence from French Local Labor Markets'. Journal of Regional Science, 53(3): 41141.

Mendez, O. (2015). 'The Effect of Chinese Import Competition on Mexican Local Labor Markets'. The North American Journal of Economics and Finance, 34(11): 364-80. 
Milberg, W., and W. Deborah (2013). Outsourcing Economics. Cambridge: Cambridge University Press.

Mion, G., and L. Zhu (2013). 'Import Competition from and Offshoring to China: A Curse or Blessing for Firms?’ Journal of International Economics, 89(1): 202-15.

Morris, M., and G. Einhorn (2008). 'Globalisation, Welfare and Competitiveness: The Impacts of Chinese Imports on the South African Clothing and Textile Industry'. Competition and Change, 12(4): $355-76$.

Morrison, A., C. Pietrobelli, and R. Rabellotti (2008). 'Global Value Chains and Technological Capabilities: A Framework to Study Industrial Innovation in Developing Countries'. Oxford Development Studies, 36(1): 39-58.

Newman, C., J. Rand, T. Talbot, and F. Tarp (2015). 'Technology Transfers, Foreign Investment and Productivity Spillovers'. European Economic Review, 76(5): 168-87.

OECD-TiVA (2018). 'Trade in Value Added, 2018'. OECD-TiVA dataset. Available at: https://stats.oecd.org/Index.aspx?DataSetCode=TIVA_2018_C1\&_ga=2.219893785. $1217116039.1547113689-475570617.1547113689$, accessed January 2019.

Paz, L.S. (2018). 'The Effect of Import Competition on Brazil's Manufacturing Labor Market in the 2000s: Are Imports from China Different?'. The International Trade Journal, 32 (1): 76-99.

Penrose, E.T. (1959). The Theory of the Growth of the Firm. Oxford: Oxford University Press.

Pierce, J.R., and P.K. Schott (2016). 'The Surprisingly Swift Decline of U.S. Manufacturing Employment'. American Economic Review, 106(7): 1632-62.

Rodrik, D. (2006). 'What's so Special about China's Exports?'. China \& World Economy, 14(5): 1-19.

Rodrik, D. (2008). 'Understanding South Africa's Economic Puzzles'. The Economics of Transition, 16(4): 769-97.

Schott, P.K., C. Fuest, and K. O'Rourke (2008). 'The Relative Sophistication of Chinese Exports' . Economic Policy, 23(53): 5-49.

Shanmugam, K., and S. Bhaduri (2002). 'Size, Age and Firm Growth in the Indian Manufacturing Sector'. Applied Economics Letters, 9(9): 607-13.

South African Government (2018). 'Remarks by President Cyril Ramaphosa during the Forum on China-Africa Cooperation Opening Ceremony, 2018'. Available at: www.gov.za/speeches, accessed 14 October 2018.

Statistics South Africa (2018a). 'Quarterly Employment Statistics - P3041.2'. Available at: http:// beta2. statssa.gov.za, accessed July 2018.

Statistics South Africa (2018b). 'Manufacturing: Production and Sales - P3041.2'. Available at: http: //beta2.statssa.gov.za, accessed July 2018.

Steenkamp, A., M. Schaffer, W. Flowerday, and J.G. Goddard (2018). 'Innovation Activity in South Africa: Measuring the Returns to R\&D'. SA-TIED Working Paper, 5. Washington, DC: World Bank.

Tassey, G. (2014). 'Competing in Advanced Manufacturing: The Need for Improved Growth Models and Policies'. Journal of Economic Perspectives, 28(1): 27-48.

Tregenna, F. (2016). 'A Sectoral View of Employment-Intensity in South Africa'. In A. Black (ed.), Towards Employment Intensive Growth in South Africa. Cape Town: UCT Press. 
UN Comtrade (2018). 'United Nations COMTRADE Database'. Available at: https : / comtrade .un . org, accessed July 2018.

UNCTAD (2017). Handbook of Statistics. Geneva: UNCTAD.

World Bank (2018). 'GDP Per Capita Series (Constant 2010 USD), 2018'. World Bank Indicators. Available at: https://data.worldbank.org/indicator, accessed July 2018.

Zhou, Y., W. Lazonick, and S. Yifei (2016). China as an Innovation Nation. Oxford: Oxford University Press. 


\section{Appendix}

Table A1: Summary statistics, 2010-17.

\begin{tabular}{lcc}
\hline Variable & Mean & Std dev. \\
\hline$\Delta \log (\text { Employment })_{i}$ & 0.025 & 0.498 \\
$\Delta \log (\text { Sales })_{i}$ & 0.017 & 0.493 \\
Death $_{i}$ & 0.028 & 0.167 \\
$\log (E)_{i}$ & 2.579 & 1.423 \\
$\log \left(\right.$ Age $_{i}$ & 2.608 & 0.659 \\
INVST $_{i}$ & $5.08 \%$ & $13.45 \%$ \\
INNOV $_{i}$ & $0.13 \%$ & $2.17 \%$ \\
TRAIN $_{i}$ & $0.08 \%$ & $2.58 \%$ \\
INVST $_{i}$ (d) & 0.646 & 0.480 \\
INNOV $_{i}$ (d) & 0.066 & 0.242 \\
TRAIN $_{i}$ (d) & 0.105 & 0.306 \\
PEN $_{s}^{c h n}$ & 0.0945 & 0.0972 \\
\hline
\end{tabular}

Source: authors' calculations using SARS data. 
Table A2: South Africa's low-wage trade partners from 2010 to 2017 (excluding China).

\begin{tabular}{|c|c|c|}
\hline Afghanistan & Ethiopia & Nicaragua \\
\hline Albania & Fiji & Niger \\
\hline Algeria & Gambia & Nigeria \\
\hline Angola & Georgia & Pakistan \\
\hline Armenia & Ghana & Papua New Guinea \\
\hline Azerbaijan & Guatemala & Paraguay \\
\hline Bangladesh & Guinea & Peru \\
\hline Belarus & Guyana & Philippines \\
\hline Belize & Haiti & Rep. of Moldova \\
\hline Benin & Honduras & Rwanda \\
\hline Bhutan & India & St. Vincent and the Grenadine \\
\hline Bolivia & Indonesia & Samoa \\
\hline Bosnia Hezeg. & Iran & Sao Tome and Principe \\
\hline Botswana & Iraq & Senegal \\
\hline Bulgaria & Jamaica & Serbia \\
\hline Burkina Faso & Jordan & Sierra Leone \\
\hline Burundi & Kenya & Solomon Islands \\
\hline Cabo Verde & Kiribati & Sri Lanka \\
\hline Cambodia & Kyrgyzstan & Swaziland \\
\hline Cameroon & Lao People's Dem. Rep. & Tajikistan \\
\hline Central African Rep. & Lesotho & Thailand \\
\hline Chad & Liberia & Timor-Leste \\
\hline Colombia & Macedonia & Togo \\
\hline Comoros & Madagascar & Tonga \\
\hline Congo & Malawi & Tunisia \\
\hline Cuba & Mali & Turkmenistan \\
\hline Cote d'Ivoire & Marshall Islands & Uganda \\
\hline Dem. Rep. of the Congo & Mauritania & Ukraine \\
\hline Djibouti & Mongolia & United Rep. of Tanzania \\
\hline Dominica & Morocco & Uzbekistan \\
\hline Dominican Rep. & Mozambique & Viet Nam \\
\hline Ecuador & Myanmar & Yemen \\
\hline Egypt & Namibia & Zambia \\
\hline El Salvador & Nepal & Zimbabwe \\
\hline
\end{tabular}

Source: authors' calculations based on constant GDP per capita (US\$2010) from the World Bank (2018). 
Table A3: Breakdown of industries depending on their technological classification.

\begin{tabular}{|c|c|c|}
\hline Code & Description & Technology class \\
\hline 301 & Meat, fish, fruit, etc. & \\
\hline 302 & Dairy products & \\
\hline 303 & Grain mill prod., animal feeds & \\
\hline 304 & Other food products & \\
\hline 305 & Beverages & \\
\hline 321 & Sawmilling, planing of wood & \\
\hline 322 & Wood, wood products & Resource-based \\
\hline 323 & Paper, paper products & \\
\hline $331 / 2$ & Coke oven, petroleum products & \\
\hline 337 & Rubber products & \\
\hline 341 & Glass, glass products & \\
\hline 342 & Non-metallic mineral products & \\
\hline 311 & Spinning, weaving of textiles & \\
\hline 312 & Other textiles & \\
\hline 313 & Knitted, crocheted fabrics & \\
\hline $314 / 5$ & Clothing & \\
\hline 316 & Leather, leather products & \\
\hline 317 & Footwear & Low-tech \\
\hline $324 / 5 / 6$ & Publishing, printing, rel. serv. & \\
\hline 354 & Structural steel products & \\
\hline 355 & Other fabricated metal products & \\
\hline 391 & Furniture & \\
\hline 392 & Other manufacturing & \\
\hline 334 & Basic chemicals & \\
\hline $335 / 6$ & Other chemicals & \\
\hline 338 & Plastic products & \\
\hline 351 & Basic iron, steel & \\
\hline 352 & Non-ferrous metals & \\
\hline $356 / 9$ & General-purpose machinery & \\
\hline 357 & Special-purpose machinery & \\
\hline 358 & Household appliance & \\
\hline $361 / 2$ & Electrical equip., apparatus & \\
\hline 363 & Insulated wire, cable & Medium- to high-tech \\
\hline 364 & Accumulators, batteries & \\
\hline 365 & Electric lamps, lighting equip. & \\
\hline 366 & Other electrical equipment & \\
\hline $371 / 2 / 3$ & TV, radio, other electronic equip. & \\
\hline $374 / 5 / 6$ & Medical, measuring, controlling equip. & \\
\hline 381 & Motor vehicles & \\
\hline 382 & Bodies for motor vehicles & \\
\hline 383 & Parts, accessories for motor vehicles & \\
\hline $384 / 5 / 6 / 7$ & Other transport equipment & \\
\hline
\end{tabular}

Source: authors, based on Lall (2000). 
Figure A1: First-stage regression, 2010-2016.

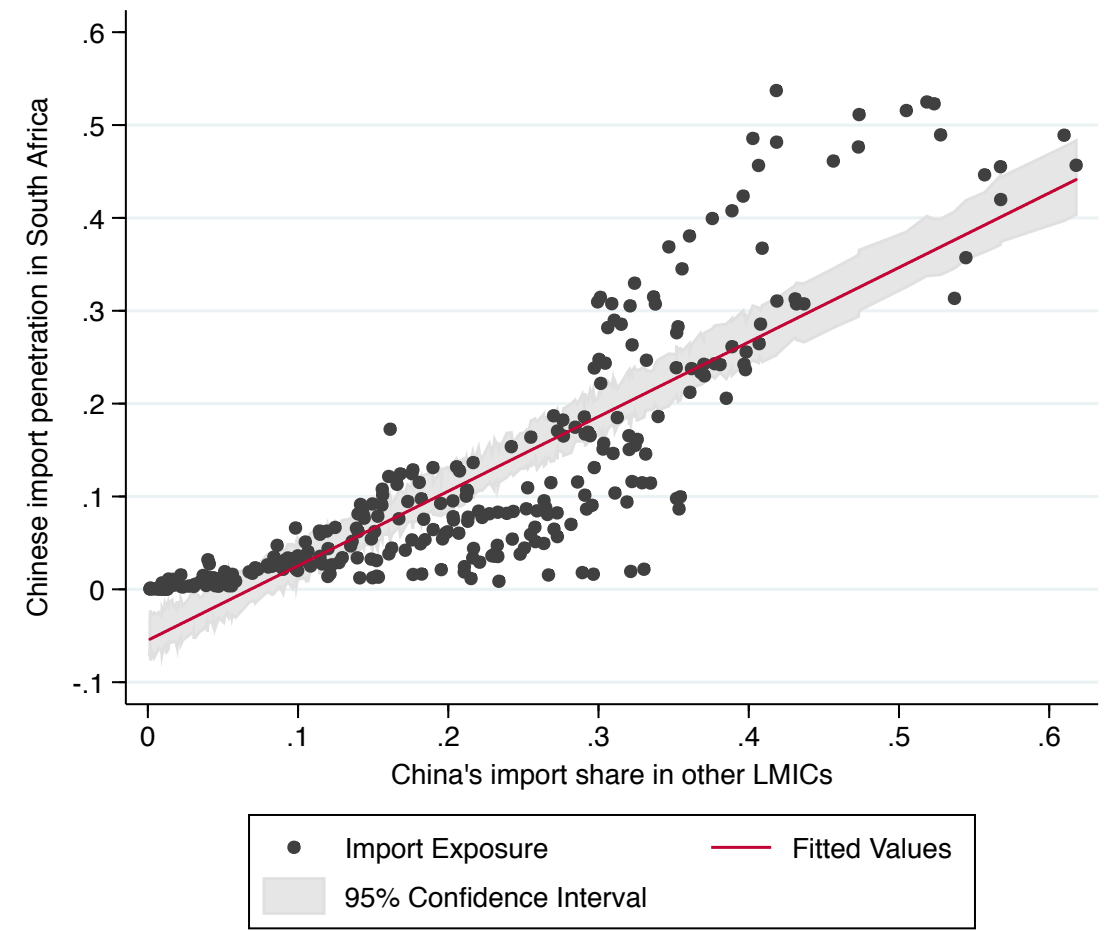

Notes: each point represents a manufacturing industry in a specific year, from 2010 to $2016(N=294)$. The South African exposure to Chinese imports is defined as the South African imports from China divided by South African apparent consumption; the comparison countries' exposure to Chinese imports is defined as China's share in other low- and middle-income country imports. Lines are fitted by OLS regression. The 95 per cent confidence interval is based on robust standard errors. The slope coefficient is 0.8 with robust standard error 0.03 ; the $t$-statistic, $F$-statistic and R-squared are 24.35 , 85.8 , and 0.73 , respectively. Time controls included.

Source: authors' compilation based on data. 


\section{A1.1 Threats to identification strategy}

As already anticipated in the subsection 'Instrumenting Chinese import penetration', our identification strategy presents a number of potential shortcomings.

First, as pointed out by Autor et al. (2013), in some sectors, import demand shocks might correlate across less developed economies. In this case IV estimates of the coefficient of Chinese import penetration would likely be biased. As an example, in the case of employment growth, the impact of trade exposure would appear smaller than it is in reality. In order to address this problem, we might re-estimate our regression models excluding those sectors that may give rise to such an issue. In this respect, a relevant example is represented by consumer electronics. Indeed, in such sectors the increase of Chinese imports both to South Africa and other developing economies might be driven from a combination of rising domestic demand (e.g. for mobile phones) and growing Chinese productivity and manufacturing capacity (so that components are sourced from Chinese suppliers rather than, say, Japanese or Korean ones). For these, even employing the above-mentioned instrumental approach, we might not capture the real effect that rising Chinese imports would have on South Africa-based manufacturing firms. Consistently with this reasoning, in an additional exercise (see Table A4), we exclude consumer electronics industries (e.g. accumulators and batteries, electric lamps, communication electronic equipment, and domestic appliances) from our estimates on employment growth. Results confirm that the impact of import exposure becomes slightly larger.

A second concern is that increasing Chinese imports might be driven by South African-rather than Chinese-changes in productivity and manufacturing capacity. If, for instance, the South Africa-based producers of earth-moving equipment experience a stagnation or a decrease in their productivity and competitiveness, then their sales might decline both in South Africa and in other developing economies, leading each to increase their imports of earth-moving equipment from third countries, including China. While this possibility cannot be ruled out analytically, existing literature and evidence suggest that the dramatic upgrade in productivity and manufacturing capacity in China is likely to be the key driver of Chinese export increases over the last three decades, including the specific period of interest for this study.

Third, our analysis focuses on the 2010-17 period, which follows the timespan considered in previous works (Acemoglu et al. 2016; Alvarez and Claro 2009; Autor et al. 2013; Bernard et al. 2006; Mion and Zhu 2013). However, even if the bulk of China's increase in absolute and relative manufacturing capacity precedes the sample period under examination (from the mid-1990s to 2007), a significant process of expansion and consolidation of the country's global heft can also be observed immediately after the financial crisis. Between 2010 and 2017, for example, China experienced a 65 per cent increase in its manufacturing value-added (MVA), accounting for over 70 per cent of the worldwide increase in MVA that occurred in low- and middle-income economies. ${ }^{46}$ Moreover, China has been responsible for over 40 per cent and 53 per cent of the total increase in global manufacturing imports in the aftermath of the financial crisis in South Africa and other low- and middle-income countries, respectively, while accounting for only 19 per cent and 14 per cent of such growth over the 1992-2007 period.

\footnotetext{
${ }^{46}$ As reported by Autor et al. (2013), between 1992 and 2007, China accounted for three-quarters of the worldwide growth in MVA experienced by the group of low- and middle-income countries.
} 
Table A4: Import competition analysis excluding 358, 364, 365, 372: employment growth: $\Delta \log (E)_{i, t+1}$.

\begin{tabular}{|c|c|c|}
\hline Dep. variable & $\Delta \log (E)_{i, t+1}$ & \\
\hline Specification & (1) & (2) \\
\hline Estimation method & IV & IV \\
\hline \multicolumn{3}{|c|}{ Import exposure variable } \\
\hline$P E N_{s, t}^{c h n}$ & $\begin{array}{c}-1.489^{* * *} \\
(0.401)\end{array}$ & $\begin{array}{c}-1.748^{* * *} \\
(0.516)\end{array}$ \\
\hline$\times$ (d) $I N V S T_{i, t}$ & $\begin{array}{c}0.230^{* * *} \\
(0.023)\end{array}$ & $\begin{array}{c}0.243^{* * *} \\
(0.026)\end{array}$ \\
\hline$\times$ (d) $I N N O V_{i, t}$ & $\begin{array}{l}0.134^{* *} \\
(0.055)\end{array}$ & $\begin{array}{l}0.144^{* *} \\
(0.061)\end{array}$ \\
\hline$\times$ (d) $\operatorname{TRAIN}_{i, t}$ & $\begin{array}{c}0.149^{* * *} \\
(0.034)\end{array}$ & $\begin{array}{c}0.171^{* * *} \\
(0.040)\end{array}$ \\
\hline Firm fixed effects & Yes & Yes \\
\hline Year dummies & Yes & Yes \\
\hline Observations & 90,530 & 88,986 \\
\hline R-squared & 0.3162 & 0.3130 \\
\hline Number of firms & 12,959 & 12,738 \\
\hline
\end{tabular}

Notes:

1. Dep. var. is the log difference of firm employment between $t$ and $t+1$.

2. All specifications include the constant and all controls.

3. All estimates refer to the subset of surviving firms.

4. (1) reports IV estimates with $358,364,365,372$; (2) excludes them.

5. China's import share in other low- and middle-income countries is used as the IV for PEN $N_{s, t}^{c h}$.

6. Standard errors in parentheses, clustered at both industry and firm level.

${ }^{*} p<0.10,{ }^{* *} p<0.05,{ }^{* * *} p<0.01$

Source: authors' calculations using SARS data. 
Table A5: Average percentage of firms investing in capabilities and average intensity of investments by sector, $2010-17$.

\begin{tabular}{|c|c|c|c|c|c|c|c|}
\hline \multirow[b]{2}{*}{ Code } & \multirow[b]{2}{*}{ Description } & \multicolumn{2}{|c|}{ Investment } & \multicolumn{2}{|c|}{ Innovation } & \multicolumn{2}{|c|}{ Training } \\
\hline & & $\%$ & ints. (\%) & $\%$ & ints. (\%) & $\%$ & ints. (\%) \\
\hline & Resource-based & & & & & & \\
\hline 301 & Meat, fish, fruit, etc. & 68 & 5.4 & 8 & 0.12 & 14 & 0.04 \\
\hline 302 & Dairy products & 71 & 6.4 & 12 & 0.41 & 16 & 0.11 \\
\hline 303 & Grain mill prod., animal feeds & 66 & 5.0 & 14 & 0.15 & 17 & 0.32 \\
\hline 304 & Other food products & 68 & 5.0 & 12 & 0.30 & 15 & 0.07 \\
\hline 305 & Beverages & 68 & 14.0 & 13 & 0.75 & 19 & 0.92 \\
\hline 321 & Sawmilling, planing of wood & 68 & 6.8 & 2 & 0.07 & 11 & 0.01 \\
\hline 322 & Wood, wood products & 60 & 4.5 & 2 & 0.04 & 5 & 0.02 \\
\hline 323 & Paper, paper products & 66 & 5.5 & 5 & 0.05 & 12 & 0.09 \\
\hline $331 / 2$ & Coke oven, petroleum products & 62 & 4.4 & 13 & 0.11 & 21 & 0.49 \\
\hline 337 & Rubber products & 63 & 4.8 & 6 & 0.13 & 10 & 0.16 \\
\hline 341 & Glass, glass products & 69 & 5.5 & 7 & 0.10 & 10 & 0.03 \\
\hline \multirow[t]{2}{*}{342} & Non-metallic mineral products & 65 & 6.5 & 9 & 0.14 & 13 & 0.05 \\
\hline & Low-tech & & & & & & \\
\hline 311 & Spinning, weaving of textiles & 60 & 5.4 & 5 & 0.09 & 8 & 0.02 \\
\hline 312 & Other textiles & 61 & 4.3 & 5 & 0.06 & 7 & 0.01 \\
\hline 313 & Knitted, crocheted fabrics & 58 & 5.4 & 2 & 0.02 & 7 & 0.01 \\
\hline $314 / 5$ & Clothing & 59 & 3.4 & 5 & 0.07 & 5 & 0.01 \\
\hline 316 & Leather, leather products & 59 & 3.9 & 4 & 0.04 & 7 & 0.01 \\
\hline 317 & Footwear & 61 & 3.0 & 9 & 0.16 & 9 & 0.01 \\
\hline $324 / 5 / 6$ & Publishing, printing, rel. serv. & 64 & 6.4 & 2 & 0.08 & 6 & 0.01 \\
\hline 354 & Structural steel products & 64 & 5.0 & 3 & 0.02 & 9 & 0.03 \\
\hline 355 & Other fabricated metal products & 64 & 5.5 & 4 & 0.06 & 10 & 0.10 \\
\hline 391 & Furniture & 60 & 4.2 & 3 & 0.03 & 5 & 0.01 \\
\hline \multirow[t]{2}{*}{392} & Other manufacturing & 62 & 5.0 & 6 & 0.11 & 8 & 0.05 \\
\hline & Medium- to high-tech & & & & & & \\
\hline 334 & Basic chemicals & 66 & 4.3 & 11 & 0.12 & 16 & 0.02 \\
\hline $335 / 6$ & Other chemicals & 68 & 4.5 & 12 & 0.36 & 16 & 0.26 \\
\hline 338 & Plastic products & 66 & 5.8 & 5 & 0.08 & 11 & 0.06 \\
\hline 351 & Basic iron, steel & 63 & 5.2 & 4 & 0.07 & 10 & 0.07 \\
\hline 352 & Non-ferrous metals & 64 & 4.8 & 4 & 0.02 & 11 & 0.01 \\
\hline $356 / 9$ & General-purpose machinery & 67 & 4.6 & 5 & 0.10 & 11 & 0.04 \\
\hline 357 & Special-purpose machinery & 68 & 4.8 & 10 & 0.14 & 13 & 0.02 \\
\hline 358 & Household appliance & 71 & 3.6 & 9 & 0.04 & 20 & 0.02 \\
\hline $361 / 2$ & Electrical equip., apparatus & 70 & 4.1 & 7 & 0.10 & 14 & 0.13 \\
\hline 363 & Insulated wire, cable & 70 & 3.7 & 7 & 0.09 & 17 & 0.41 \\
\hline 364 & Accumulators, batteries & 77 & 3.3 & 16 & 0.02 & 20 & 0.05 \\
\hline 365 & Electric lamps, lighting equip. & 62 & 2.4 & 7 & 0.02 & 12 & 0.01 \\
\hline 366 & Other electrical equipment & 66 & 3.8 & 8 & 0.27 & 10 & 0.05 \\
\hline $371 / 2 / 3$ & TV, radio, other electronic equip. & 68 & 4.2 & 8 & 0.31 & 10 & 0.06 \\
\hline $374 / 5 / 6$ & Medical, measuring, controlling equip. & 69 & 4.6 & 16 & 0.72 & 11 & 0.03 \\
\hline 381 & Motor vehicles & 57 & 6.2 & 16 & 0.30 & 16 & 0.01 \\
\hline 382 & Bodies for motor vehicles & 65 & 3.9 & 4 & 0.01 & 13 & 0.02 \\
\hline 383 & Parts, accessories for motor vehicles & 67 & 4.7 & 21 & 0.47 & 22 & 0.04 \\
\hline $384 / 5 / 6 / 7$ & Other transport equipment & 64 & 4.4 & 8 & 0.20 & 16 & 0.08 \\
\hline- & Total & 64 & 5.1 & 6 & 0.13 & 10 & 0.08 \\
\hline
\end{tabular}

Source: authors' calculations using SARS data. 
Table A6: Average percentage of firms investing in capabilities and average intensity of investments by size, $2010-17$.

\begin{tabular}{lcccccccc}
\hline & \multicolumn{2}{c}{ Investment } & & \multicolumn{2}{c}{ Innovation } & & \multicolumn{2}{c}{ Training } \\
\cline { 2 - 3 } \cline { 8 - 9 } Description & $\%$ & ints. (\%) & & $\%$ & ints. (\%) & & $\%$ & ints. (\%) \\
\hline Micro & 57 & 5.1 & & 2 & 0.09 & & 3 & 0.06 \\
Small & 73 & 4.8 & & 7 & 0.12 & & 15 & 0.08 \\
Medium & 77 & 5.0 & & 15 & 0.20 & & 31 & 0.14 \\
Large & 79 & 5.3 & & 36 & 0.50 & & 45 & 0.30 \\
\hline Total & 64 & 5.1 & & 6 & 0.13 & & 10 & 0.08 \\
\hline
\end{tabular}

Notes: size is defined with respect to firms' full-time equivalent employment according to the March 2016/17 cut-off published on the National Small Business Survey. Firms are defined as micro when employing fewer than 20 people, small and medium when employing 20-49 and 50-199 people, respectively, and large when employing more than 199 workers.

Source: authors' calculations using SARS data.

Figure A2: Change in Chinese import penetration over 2010-16 and average sectoral training intensity in 2010.

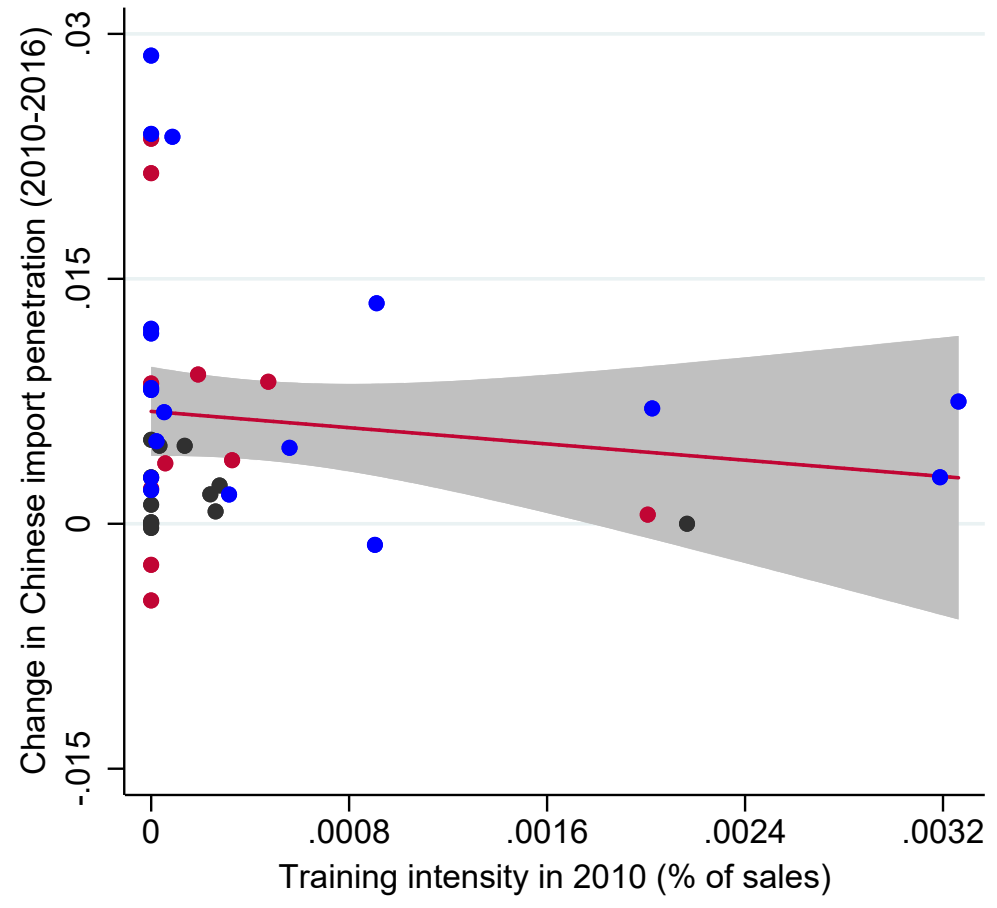

Notes: each point represents a manufacturing industry $(N=42)$. The change in Chinese import penetration to South Africa is defined as the average annual change between 2010 and 2016; the average industry-level training intensities in 2010 is the spending in training normalized by total sales-TRAIN $)_{i, 2010}$.

Source: authors' calculations using UN Comtrade (2018) and SARS data. 
Table A7: Direct import penetration analysis, OLS estimates.

\begin{tabular}{|c|c|c|c|}
\hline Dep. variable & $\Delta \log (E)_{i, t+1}$ & $\Delta \log (S)_{i, t+1}$ & Death $_{i, t+1}$ \\
\hline Specification & (1) & (2) & (3) \\
\hline Estimation method & OLS & OLS & OLS \\
\hline \multicolumn{4}{|l|}{ Controls } \\
\hline $\log (E)_{i, t}$ & $\begin{array}{c}-0.395^{* * *} \\
(0.006)\end{array}$ & $\begin{array}{c}-0.364^{* * *} \\
(0.010)\end{array}$ & $\begin{array}{c}-0.054^{* * *} \\
(0.002)\end{array}$ \\
\hline $\log (A g e)_{i, t}$ & $\begin{array}{c}0.077^{* * *} \\
(0.014)\end{array}$ & $\begin{array}{c}0.060^{* * *} \\
(0.014)\end{array}$ & $\begin{array}{c}0.130^{* * *} \\
(0.006)\end{array}$ \\
\hline$I N V S T_{i, t}$ & $\begin{array}{c}0.004^{* * *} \\
(0.002)\end{array}$ & $\begin{array}{c}0.001^{* * *} \\
(0.001)\end{array}$ & $\begin{array}{c}-0.002^{* * *} \\
(0.001)\end{array}$ \\
\hline INNOV $_{i, t}$ & $\begin{array}{c}0.001^{* * *} \\
(0.001)\end{array}$ & $\begin{array}{c}0.003 \\
(0.002)\end{array}$ & $\begin{array}{c}-0.001^{* *} \\
(0.001)\end{array}$ \\
\hline TRAIN $_{i, t}$ & $\begin{array}{l}-0.001 \\
(0.001)\end{array}$ & $\begin{array}{l}-0.001 \\
(0.001)\end{array}$ & $\begin{array}{c}-0.001^{* * *} \\
(0.001)\end{array}$ \\
\hline \multicolumn{4}{|c|}{ Import exposure variables } \\
\hline$P E N_{s, t}^{c h n}$ & $\begin{array}{c}-0.738^{* * *} \\
(0.237)\end{array}$ & $\begin{array}{c}-0.912^{* * *} \\
(0.273)\end{array}$ & $\begin{array}{c}0.275^{* *} \\
(0.102)\end{array}$ \\
\hline$\times$ (d) $I N V S T_{i, t}$ & $\begin{array}{c}0.341^{* * *} \\
(0.051)\end{array}$ & $\begin{array}{c}0.172^{* * *} \\
(0.061)\end{array}$ & $\begin{array}{c}-0.152^{* * *} \\
(0.033)\end{array}$ \\
\hline$\times$ (d) $I N N O V_{i, t}$ & $\begin{array}{c}0.166^{* * *} \\
(0.158)\end{array}$ & $\begin{array}{c}0.051 \\
(0.139)\end{array}$ & $\begin{array}{c}-0.033^{*} \\
(0.018)\end{array}$ \\
\hline$\times$ (d) $T R A I N_{i, t}$ & $\begin{array}{c}0.084^{* * *} \\
(0.026)\end{array}$ & $\begin{array}{l}-0.099 \\
(0.076)\end{array}$ & $\begin{array}{c}-0.126^{* * *} \\
(0.012)\end{array}$ \\
\hline Constant & $\begin{array}{c}0.958^{* * *} \\
(0.039)\end{array}$ & $\begin{array}{c}5.749^{* * *} \\
(0.154)\end{array}$ & $\begin{array}{c}-0.169^{* * *} \\
(0.013)\end{array}$ \\
\hline Firm fixed effects & Yes & Yes & Yes \\
\hline Year dummies & Yes & Yes & Yes \\
\hline Observations & 90,530 & 86,287 & 134,395 \\
\hline R-squared & 0.3214 & 0.2242 & 0.0773 \\
\hline Number of firms & 12,959 & 12,919 & 23,170 \\
\hline \multicolumn{4}{|c|}{$\begin{array}{l}\text { Notes: } \\
\text { 1. A linear probability model is used in (3). } \\
\text { 2. Estimates in (1) and (2) refer to the subset of surviving firms. } \\
\text { 3. All specifications report OLS estimates. } \\
\text { 4. Standard errors are clustered at both industry and firm level. } \\
{ }^{*} p<0.10,{ }^{* *} p<0.05,{ }^{* * *} p<0.01 \text {. }\end{array}$} \\
\hline
\end{tabular}


Table A8: Direct import penetration analysis, with $P E N_{s, t}^{l o w}$ and $P E N_{s, t}^{\text {oth }}$.

\begin{tabular}{|c|c|c|c|}
\hline Dep. variable & $\Delta \log (E)_{i, t+1}$ & $\Delta \log (S)_{i, t+1}$ & Death $_{i, t+1}$ \\
\hline Specification & (1) & (2) & (3) \\
\hline Estimation method & IV & IV & IV \\
\hline \multicolumn{4}{|l|}{ Controls } \\
\hline $\log (E)_{i, t}$ & $\begin{array}{c}-0.394^{* * *} \\
(0.006)\end{array}$ & $\begin{array}{c}-0.363^{* * *} \\
(0.010)\end{array}$ & $\begin{array}{c}-0.056^{* * *} \\
(0.002)\end{array}$ \\
\hline $\log (A g e)_{i, t}$ & $\begin{array}{c}0.075^{* * *} \\
(0.014)\end{array}$ & $\begin{array}{c}0.059^{* * *} \\
(0.014)\end{array}$ & $\begin{array}{c}0.127^{* * *} \\
(0.006)\end{array}$ \\
\hline$I N V S T_{i, t}$ & $\begin{array}{c}0.004^{* * *} \\
(0.002)\end{array}$ & $\begin{array}{c}0.001^{* * *} \\
(0.001)\end{array}$ & $\begin{array}{c}-0.002^{* * *} \\
(0.001)\end{array}$ \\
\hline INNOV $_{i, t}$ & $\begin{array}{c}0.001^{* * *} \\
(0.001)\end{array}$ & $\begin{array}{c}0.003 \\
(0.002)\end{array}$ & $\begin{array}{c}-0.001^{* *} \\
(0.001)\end{array}$ \\
\hline $\operatorname{TRAIN}_{i, t}$ & $\begin{array}{l}-0.001 \\
(0.001)\end{array}$ & $\begin{array}{l}-0.001 \\
(0.001)\end{array}$ & $\begin{array}{c}-0.001^{* * *} \\
(0.001)\end{array}$ \\
\hline \multicolumn{4}{|c|}{ Import exposure variables } \\
\hline$P E N_{s, t}^{c h n}$ & $\begin{array}{c}-1.228^{* * *} \\
(0.124)\end{array}$ & $\begin{array}{c}-1.259^{* * *} \\
(0.357)\end{array}$ & $\begin{array}{c}0.204 \\
(0.180)\end{array}$ \\
\hline$P E N_{s, t}^{l o w}$ & $\begin{array}{l}-0.096 \\
(0.118)\end{array}$ & $\begin{array}{l}-0.071 \\
(0.116)\end{array}$ & $\begin{array}{c}0.002 \\
(0.058)\end{array}$ \\
\hline$P E N_{s, t}^{o t h}$ & $\begin{array}{c}-0.332^{* * *} \\
(0.135)\end{array}$ & $\begin{array}{c}-0.388^{* * *} \\
(0.139)\end{array}$ & $\begin{array}{c}0.047 \\
(0.061)\end{array}$ \\
\hline Constant & $\begin{array}{c}1.058^{* * *} \\
(0.049)\end{array}$ & $\begin{array}{c}5.898^{* * *} \\
(0.161)\end{array}$ & $\begin{array}{c}-0.183^{* * *} \\
(0.026)\end{array}$ \\
\hline Firm fixed effects & Yes & Yes & Yes \\
\hline Year dummies & Yes & Yes & Yes \\
\hline Observations & 90,530 & 86,287 & 134,395 \\
\hline R-squared & 0.3170 & 0.2210 & 0.0735 \\
\hline Number of firms & 12,959 & 12,919 & 23,170 \\
\hline
\end{tabular}

Notes:

1. A linear probability model is used in (3).

2. Estimates in (1) and (2) refer to the subset of surviving firms.

3. All specifications report IV estimates.

4. China's import share in other low- and middle-income countries is used as the IV for $P E N_{s, t}^{c h n}$.

5. Standard errors are clustered at both industry and firm level.

${ }^{*} p<0.10,{ }^{* *} p<0.05,{ }^{* * *} p<0.01$.

Source: authors' calculations using SARS data. 